\title{
EMPREENDER COMO UMA FORMA DE SER, SABER E FAZER
}

ENTREPRENEURSHIP AS A WAY OF BEING, KNOWING AND DOING

Recebido em 25.08.2019 Aprovado em 06.03.2020

Avaliado pelo sistema double blind review

DOI: https://doi.org/10.12712/rpca.v14i1.34722

\section{Ricardo Schaefer}

ricardoschaefer@libero.it

Programa de Pós-graduação em Administração/Universidade Federal de Santa Maria- Santa Maria/RS, Brasil

ORCID: https://orcid.org/0000-0003-0518-3080

\section{Italo Fernando Minello}

minelloif@gmail.com

Programa de Pós-graduação em Administração/Universidade Federal de Santa Maria- Santa Maria/RS, Brasil ORCID: https://orcid.org/0000-0001-5240-8196

\section{Resumo}

Este trabalho teve como objetivo analisar o desenvolvimento da mentalidade e comportamento empreendedores em alunos e professores de uma instituição de ensino superior, por meio da educação empreendedora. Realizou-se um estudo qualitativo e quantitativo, do tipo exploratório, com base em pesquisa teórico-empírica e triangulação dos dados. Os resultados evidenciaram características e especificidades da natureza da educação empreendedora, os novos papéis que alunos e professores assumem, novas metodologias e práticas pedagógicas, um processo educacional não apenas orientado à transmissão de conhecimentos, mas sobretudo voltado ao empreender como uma forma de ser, saber e fazer.

Palavras-chave: Educação empreendedor. Aprendizagem empreendedora. Mentalidade empreendedora. Comportamento empreendedor. Ser empreendedor.

\begin{abstract}
This study aimed to analyze the development of entrepreneurial mindset and behavior in students and professors of a higher education institution, through entrepreneurial education. A qualitative and quantitative exploratory study was conducted, based on theoretical-empirical research and data triangulation. The results showed characteristics and specificities of the nature of entrepreneurial education, the new roles that students and professors assume, new methodologies and pedagogical practices, and an educational process not only oriented to the transmission of knowledge, but above all focused on entrepreneurship as a way of being, knowing. and doing.
\end{abstract}

Keywords: Entrepreneurial education. Entrepreneurial learning. Entrepreneurial mindset. Entrepreneurial behavior. being an entrepreneur. 


\section{Introdução}

Os estudos sobre a formação de empreendedores cresceram significativamente nos últimos anos, estimulando novos entendimentos sobre o ser empreendedor e o papel do ensino superior no seu desenvolvimento. A educação empreendedora tem sido investigada por pesquisas de diferentes áreas na medida em que desempenha um papel fundamental na criação e propagação da cultura empreendedora na sociedade atual (Nabi, et. al. 2018). A partir dela, a atividade empreendedora se potencializa, mostrando-se vital para a economia de um país, visto que por meio dela se instruem e preparam indivíduos com conhecimentos e habilidades necessários para perceberem obstáculos como oportunidades, aproveitando as situações e o contexto para criarem empreendimentos e gerarem, como consequência, desenvolvimento econômico e social (Silva; Pena, 2017; Duarte; Debova; Perini, 2018).

Em relação ao Brasil, existe a necessidade - e consequente oportunidade - de se potencializar "uma educação empreendedora que permita que uma maior proporção do seu capital humano desenvolva o seu potencial empreendedor" (Dolabela; Filion, 2013, p. 154). A educação empreendedora pode assim aumentar a quantidade e qualidade dos jovens inovadores, proativos e com iniciativa, tanto para criarem empreendimentos próprios quanto para trabalharem em uma organização ou atividade autônoma com atitude e características empreendedoras (Lima et. al., 2014a; Krüger; 2019).

A formação empreendedora, porém, deve adotar uma metodologia e práticas didático-pedagógicas próprias, diferentes das utilizadas no ensino superior tradicional (Schaefer; Minello, 2016). Dolabela e Filion (2013) sustentam uma mudança radical em relação aos métodos tradicionais de ensino, que ainda se concentram na transferência linear de conhecimentos, passando a um processo de ensino e aprendizagem centrados no aluno, a fim de torná-lo progressivamente capaz de pensar e agir de modo independente e proativo.

A compreensão da natureza e perfil empreendedores e de como se manifesta o ser empreendedor podem nortear ações e projetos com o objetivo de se criarem ambientes, instituições e sujeitos empreendedores, partindo-se de uma nova proposta de educação empreendedora (Schaefer \& Minello, 2016; Amaral, Hernandez \& Bastos, 2018). Para Dolabela (2008), a "forma empreendedora de ser" está relacionada com visão de mundo, estilo de vida, protagonismo, padrões de reação diante de ambiguidades e incertezas, capacidade de produzir mudanças em si mesmo e no contexto em que vive, criação de inovação, meios e formas de se buscar a autorrealização.

Considerando essas características, o indivíduo empreendedor "se expressa através de um determinado tipo de pensamento e ação" (Dolabela \& Filion, 2013, p. 135): pensamento enquanto modo de ver e entender o mundo, e ação enquanto comportamento manifesto, decorrente do primeiro aspecto. Empreender torna-se então uma forma de ser, de saber e de fazer, com características de mentalidade (modo de pensar) e de comportamento (modo de agir) sendo desenvolvidas tanto nos alunos quanto nos professores, enquanto indivíduos empreendedores (modo de ser) (Schaefer, 2018; Schaefer \& Minello, 2019).

Diante desses desafios e da evolução dos estudos sobre formação empreendedora, este trabalho tem o objetivo de analisar o desenvolvimento da mentalidade e do comportamento empreendedores em alunos e professores de graduação de uma instituição privada de ensino superior, por meio da educação empreendedora. Deste objetivo geral, desdobraram-se 4 objetivos específicos: 1 . identificar as dimensões da mentalidade e as características do comportamento empreendedor de alunos de graduação e de docentes de diferentes cursos da instituição de ensino; 2.verificar a relação entre a mentalidade e o comportamento empreendedores em alunos e docentes; 3.verificar atividades de ensino no processo de educação empreendedora nos cursos de graduação; 4. apurar a contribuição das iniciativas de educação empreendedora para estimular o empreender como uma forma de ser, saber e fazer em alunos e professores. 


\section{Fundamentação Teórica}

\section{Educação empreendedora}

A educação empreendedora tem sido objeto de estudo de diversos pesquisadores visto que desempenha uma função prioritária na criação e disseminação da cultura empreendedora na sociedade (Nabi, et. al. 2018). A partir dela, a atividade empreendedora se potencializa, contribuindo para a economia de um país, visto que através dela se instruem e preparam indivíduos com conhecimentos e habilidades necessários para identificarem obstáculos como oportunidades, aproveitando as situações que se apresentam e o contexto em que atuam para criarem empreendimentos e gerarem, por consequência, crescimento econômico e social (Silva \& Pena, 2017; Duarte, Debona \& Perini, 2018).

A educação empreendedora, porém, deve seguir uma metodologia e proposta pedagógica próprias, diferentes das utilizadas no ensino tradicional (Schaefer \& Minello, 2017a). Dolabela e Filion (2013) defendem uma mudança radical em relação aos métodos tradicionais de ensino, que ainda tendem a se concentrarem na transferência de conhecimentos, passando a uma aprendizagem centrada no aluno capaz de pensar e agir de modo independente e proativo.

Henrique e Cunha (2008) também consideram que educação empreendedora não deve ser feita como nas demais disciplinas, de modo tradicional, devendo levar os alunos a estruturarem contextos e compreenderem as várias etapas da sua evolução. A formação empreendedora deve ainda concentrar-se mais no desenvolvimento do conhecimento e conceito de si e na aquisição de um saber fazer, muito além do que na simples transmissão de conhecimento. Dolabela e Filion (2013) acrescentam que essa nova proposta de educação deve estimular e desenvolver a confiança e a autoestima, buscando mergulhar o aluno em um sistema de ensino e aprendizagem onde haja uma relação coerente e próxima entre ele mesmo e a sua realidade circunstante.

Mendes (2011) defende também que o empreendedorismo deveria ser tratado não como uma disciplina autônoma, como é verificado em grande partes das instituições de ensino, mas integrada com as demais disciplinas, uma vez que existem diversas questões inerentes a outros campos de investigação que se entrelaçam no seu estudo. A universidade, portanto, ao se dispor a apostar na formação empreendedora, deve fazê-la de forma integrada, interdisciplinar, harmonizada e transversal. Guerra e Grazzotin (2010) também enfatizam que o empreendedorismo não deve ser discutido apenas em disciplinas isoladas, e tanto menos entre as quatro paredes da sala de aula. As autoras sustentam que a formação empreendedora deve ser vivenciada com intensidade por todos os envolvidos com o processo, em todas as direções. O professor deve levar para a sala de aula a temática de modo integrado às outras disciplinas, à instituição e à comunidade. "Cabe a todos os professores a responsabilidade de fazer com que os alunos sejam estimulados a pensar e agir com uma mentalidade empreendedora. A sala de aula, cada vez mais, tem de se transformar em laboratório de conhecimento. $\mathrm{O}$ assunto empreendedorismo deve ser tratado em todos os cursos e em todos os níveis" (Guerra \& Grazziotin, 2010, p. 83).

Essa transformação é possível, visto que essa nova abordagem é voltada não apenas ao alunos que têm a intenção de abrir as próprias empresas como empreendedores individuais, mas a todos os futuros profissionais, de diferentes áreas, que desempenhem suas atividades e profissões - de modo individual ou dentro de organizações - com valores, atitudes e comportamentos empreendedores. Lima et. al. (2015b) destacam que mesmo que os alunos não queiram ter um negócio próprio, podem ser beneficiados em sua formação com o desenvolvimento de conhecimentos e habilidades propícias à atividade empreendedora.

O Relatório do Estudo GUESSS Brasil evidencia ainda que se mostra atrativo e promissor que os estudantes se empenhem em ampliar a visão de possibilidades de carreiras, como por exemplo ser criador de um negócio (com vista a lucro ou fins sociais), ou empreendedor em uma profissão autônoma ou liberal, ou ainda ser um intraempreendedor ou empreendedor corporativo, atuando como um colaborador inovador e de iniciativa em uma organização pública ou privada. Isso ajudaria as 
instituições de ensino a cumprirem melhor seu papel e os estudantes a serem motores mais ativos do avanço social e econômico (Lima et. al., 2014b).

Para alcançar estes objetivos são necessárias novas metodologias de ensino e aprendizagem que permitam "aprender fazendo", a fim de que o aluno se depare com situações, desafios e dificuldades que o estimulem a refletir e pensar de modo diferente, buscando alternativas e soluções, e aprendendo com a experiência. A educação empreendedora, então, reúne propostas de ensino e aprendizagem orientadas à ação, como a aprendizagem experiencial, a aprendizagem pela ação, a aprendizagem contextual, a aprendizagem centrada em problemas, a aprendizagem cooperativa, entre outras (Schaefer \& Minello, 2016; Silva \& Pena, 2017, Araújo \& Davel, 2019),

A formação empreendedora, sendo assim fomentada e desenvolvida nas várias dimensões da universidade, conduz ao conceito de "universidade empreendedora". Guaranys (2010) descreve que essa proposta de universidade tem como escopo, além do ensino, da pesquisa e da extensão, o desenvolvimento econômico, formando empreendedores para dinamizar o contexto social e econômico. A autora acrescenta que a universidade empreendedora também incentiva seus estudantes das mais variadas áreas a desenvolverem competências empreendedoras. Essa formação empreendedora é articulada e abrangente, oferecida como uma segunda área de desenvolvimento de competências, e articulada em diferentes frentes e projetos: incubadoras de empresas, parques tecnológicos, núcleos de propriedade intelectual articulados com grupos de pesquisa e laboratórios, empresas juniores, eventos de empreendedorismo, ações de disseminação da cultura empreendedora e apoio a empreendimentos sociais e econômicos em comunidades, entre outros. Pode-se, portanto, "considerar a universidade empreendedora um novo tipo de universidade, já existente em outros países, porém despontando como alternativa mais adequada às necessidades de formação de recursos humanos e de desenvolvimento econômico brasileiro" (Guaranys, 2010, p. 105).

Apresentadas as especificidades da educação empreendedora e oportunidades para a formação do indivíduo empreendedor, passe-se a seguir a investigar o seu modo de pensamento que conduz à ação: a mentalidade empreendedora.

\section{Mentalidade empreendedora}

Um campo de investigação ainda promissor dentro do processo de aprendizagem que ocorre pela educação empreendedora é a mentalidade empreendedora (Schaefer \& Minello, 2017b). Filion e Lima (2010) destacam que "o desenvolvimento do campo do empreendedorismo deve ser feito não apenas pelo estudo da ação empreendedora, mas também do pensamento empreendedor e das ligações entre esses dois conceitos" (Filion \& Lima, 2010, p. 32).

Schaefer e Minello (2017b) relatam que essa mentalidade empreendedora tem despertado o interesse de autores de diferentes áreas do conhecimento (administração, educação, psicologia, etc.) que passaram a conduzir pesquisas com diferentes abordagens (cognitiva, sistêmica, construtivista, ontopsicológica, humanista etc.).

Filion e Lima (2010) também enfatizam que, para uma maior compreensão das ações e do comportamento do indivíduo empreendedor, um dos aspectos-chave que deve ser melhor compreendido refere-se aos processos que estão na base do seu pensamento, os processos a partir dos quais a ação empreendedora é primeiramente concebida e, na sequência, realizada.

O comportamento humano, e por consequência o comportamento empreendedor, é aberto, demonstrável, plástico e, por meio de experiências e estratégias de ensino, novos processos podem ser desenhados, treinados e internalizados. Um modo de se alcançar esse resultado é trabalhar sobre as representações e os processos de pensamento que estão por trás da atividade empreendedora (Barini Filho, 2008). 
Pesquisas sobre as dimensões dos modos mentais têm trazido novas compreensões do modo com que os empreendedores impactam, processam e entendem os contextos em que operam, e sua relação com o desempenho empresarial (De Toni et. al., 2014; Wood et al., 2017). Estudos nessa área têm identificado os modelos mentais dos empreendedores como uma forma de ver o mundo, como o pensamento ou a imagem arraigada na mente que influenciam os seus modos de se comportar e agir (De Toni et. al., 2014).

Os modelos mentais são importantes impulsionadores da ação empreendedora e os empreendedores são diretamente influenciados pelos seus conhecimentos constituídos, habilidades racionais e emocionais, visão de mundo e de si mesmos moldados pela sua trajetória. Os modelos mentais evoluem, tanto com as experiências de vida e amadurecimento da personalidade, quanto com processos de aprendizagem promovidos por educação ou treinamento (De Toni et. al., 2014). Barini Filho (2008) destaca que os empreendedores são capazes de abstrair novas regras da modelagem e agir de modo alinhado com novos conceitos aprendidos a partir de uma nova situação vivenciada ou conhecimento transmitido (Barini Filho, 2008).

Filion e Lima (2010) também evidenciam que se faz necessário centrar o estudo do indivíduo empreendedor sobre o ato de empreender, buscando compreender o modelo e a atitude mental que precede esse ato. A partir de imagens e representações de si e do mundo, os empreendedores impactam com oportunidades e incertezas do ambiente circunstante, projetam visões, realizam sonhos, progressivamente constroem e modelam o seu autoconceito. Os autores complementam que uma adequada compreensão das representações de si mesmo e do mundo à sua volta podem auxiliar o empreendedor no seu modo de ação e relação com a realidade circunstante.

Investigando a mentalidade adequada para um jovem empreender um percurso profissional com êxito, a partir da abordagem ontopsicológica, Mencarelli (2014) define cinco dimensões de uma mentalidade ou forma mentis empreendedora: responsabilidade, autonomia, vontade, espírito de iniciativa e resolução de problemas, e capacidade de gerir relações funcionais com os outros. O Quadro 1 descreve cada uma dessas dimensões.

Quadro 1 - Dimensões da forma mentis empreendedora

\begin{tabular}{|l|l|}
\hline Dimensões & Características do indivíduo que possui esta dimensão \\
\hline Responsabilidade & $\begin{array}{l}\text { Interroga-se sobre as causas primeiras daquilo que acontece, buscando colher as suas } \\
\text { eventuais responsabilidades. É maduro, tem um senso de responsabilidade e autocrítica } \\
\text { construtiva e não atribui ao externo as culpas ou causas dos eventos que o envolvem. }\end{array}$ \\
\hline Autonomia & $\begin{array}{l}\text { É capaz de agir livre e autonomamente, utilizando como referência o seu critério } \\
\text { individual. Age sem se fazer influenciar por pessoas ou situações, ou sem que seja } \\
\text { necessário o sustento ou assistência de terceiros: demonstra ter autonomia no operar, e } \\
\text { isto está ligado também à autoestima e à maturidade. }\end{array}$ \\
\hline Vontade & $\begin{array}{l}\text { É determinado, possui constância, empenho em direção a um objetivo individuado. Age } \\
\text { um contínuo exercício da própria intencionalidade a fim de concretizar seus projetos. }\end{array}$ \\
\hline $\begin{array}{l}\text { Espírito de } \\
\text { iniciativa e } \\
\text { resolução de } \\
\text { problemas }\end{array}$ & $\begin{array}{l}\text { Sabe ser criativo diante de situações, propondo soluçôes idôneas aos problemas. Coloca- } \\
\text { se diante de problemas de modo sintético e resolutivo. Não perde tempo, não é } \\
\text { dispersivo, e sim orientado ao resultado. Sabe reconhecer as prioridades e adequá-las em } \\
\text { uma resposta funcional. Vê o problema não como um obstáculo, mas sim como ocasião } \\
\text { para estimular a própria inteligência. }\end{array}$ \\
\hline $\begin{array}{l}\text { Capacidade de } \\
\text { gerir relações } \\
\text { funcionais com os } \\
\text { outros }\end{array}$ & $\begin{array}{l}\text { É capaz de gerir relações de modo funcional, ou seja, em vantagem e referência a um } \\
\text { escopo. É capaz de resolver uma situação sem fazer polêmica ou recorrer ao } \\
\text { assistencialismo, mas criando harmonia entre as pessoas funcionais ao escopo. Sabe gerir } \\
\text { as relações de maneira inteligente e com diplomacia. }\end{array}$ \\
\hline
\end{tabular}

Fonte: adaptado de Mencarelli (2014).

Essas dimensões da mentalidade ou forma mentis empreendedora identificadas e descritas por Mencarelli (2014) serão utilizadas para a análise dos dados da pesquisa, como será detalhado nos procedimentos metodológicos.

Descritos os aspectos relativos à mentalidade empreendedora, passe-se a seguir a descrever como esse modo de pensar define a sua maneira de agir por meio do comportamento empreendedor. 


\section{Comportamento empreendedor}

Diferentes pesquisas foram realizadas nas últimas décadas para descrever o empreendedor sob a perspectiva comportamental, bem como revisões e compilações da evolução desses estudos (Barini Filho, 2008; Coan, 2011; Krüger, 2019). O estudo da atividade empreendedora tem atraído a atenção de pesquisadores de diferentes áreas. Não apenas administradores ou economistas, mas educadores, psicólogos sociólogos e pesquisadores das áreas das ciências exatas passaram a investigar o modo de pensar e agir de empreendedores. Esse caldeirão de abordagens teóricas e metodológicas - cada qual com seus paradigmas, métodos de investigação, padrões de análise, experiências, conteúdos etc. - não poderia gerar senão visões diferenciadas sobre o conceito, enriquecendo o entendimento desse campo de estudo. Dolabela (2008, p. 78 ) destaca que "este novo olhar sobre a capacidade empreendedora transportou-a do seu berço original, a empresa - sem dele sair -, para todas as atividades humanas".

Ribas (2011) também ressalta que o comportamento empreendedor passou a ser investigado por pesquisadores de diferentes áreas de conhecimento, que passaram a estudar o "comportamento realizador do empreendedor". Esse comportamento é o anverso do conformismo com o status quo, da busca pela segurança e estabilidade, da oposição às mudanças, características da maioria das pessoas. "Ao contrário, o ser empreendedor reflete esta inquietação por criar, por fazer acontecer, por desfrutar de uma condição de ser o centro e não parte, mesmo que correndo o risco de perder tudo e se tornar nada" (Ribas, 2011, p. 37).

O comportamento empreendedor compreende as características particulares que alguns indivíduos apresentam, como percebem oportunidades empreendedoras, como pensam e processam, como se adaptam, como se predispõem à ação, enfim, como agem de forma empreendedora (Hisrich, Peters \& Shepherd, 2014). Essas características são desdobradas na visão de Minello (2014, p. 74), que entende o empreendedor como "o indivíduo que desenvolve algo inovador, tem iniciativa, capacidade de organizar e reorganizar mecanismos sociais e econômicos a fim de transformar recursos e situações para proveito prático, e aceita o risco ou o fracasso de suas ações” (Minello, 2014, p. 74).

Para Dolabela (2008), ser empreendedor não é somente acumular conhecimentos, mas possuir e demonstrar atitudes, formas de percepção do mundo e de si mesmo, comportamentos, é voltar-se para atividades em que existe o risco e a possibilidade de inovar, de ser perseverante, de conviver com a incerteza. Tschá e Cruz Neto entendem o empreendedor como um agente crítico, que reconhece e assume o poder de fazer, criar e transformar próprio do ser humano. Atuando essas capacidades, posiciona-se como "um agente transformador de realidades (como solucionador de problemas que afligem a sociedade) por meio dos empreendimentos colaborativos que desenvolve" (Tschá \& Cruz Neto, 2014, p. 70). Deste modo, o empreendedor, para ser considerado como tal, não pode estar dissociado da ação de empreender, fortemente impulsionada pela motivação de realização.

Em relação a esse aspecto do comportamento empreendedor, David McClelland (1972, 1978, 1987) destacou-se com seus estudos que investigaram a motivação para empreender associada à necessidade de realização. $\mathrm{O}$ autor desenvolveu pesquisas ao longo de quase cinco décadas e em diferentes países e culturas, estudando os aspectos comportamentais dos empreendedores, sobretudo relacionados à motivação para realizar as suas ações. O pesquisador percebeu os empreendedores como indivíduos diferenciados e passou a investigar suas principais características comportamentais, a fim de que fosse possível criar programas que estimulassem o desenvolvimento dessas características (Matias \& Martins, 2012).

Lima e Nassif (2017, p. 370) destacam que a teoria de McClelland figura "como uma das mais referidas na literatura sobre os empreendedores apresentando as necessidades como fator de motivação para o indivíduo. Esse autor desenvolveu um modelo que tem sido utilizado na base teórica de treinamentos para empreendedores". Dedicando a sua vida ao estudo do comportamento empreendedor, McClelland buscou identificar características pessoais inerentes ao empreendedor de sucesso. Seus estudos 
contribuíram para a formatação do Empretec, programa desenvolvido em nível mundial pela Organização das Nações Unidas (ONU) na década de 80 e, a partir dos seus estudos foram criados programas que projetam o desenvolvimento do comportamento empreendedor em diferentes países (Krüger, Pinheiro \& Minello, 2017).

Para McClelland (1972), portanto, o sucesso de pessoas, grupos ou até de uma nação, está na motivação, a qual pode resultar de três necessidades dominantes: realização, poder e afiliação. McClelland $(1972,1978,1987)$ observou que o ser humano normal apresenta um perfil predominante de necessidades - de realização, afiliação ou poder - que em maior ou menor grau influenciam no seu comportamento e interação com o ambiente que o cerca. $\mathrm{O}$ pesquisador identificou ainda que as pessoas com maior necessidade de realização são mais propensas a empreender e que essas competências podem ser estimuladas e desenvolvidas por meio de programas de treinamento específicos, obtendo-se com esses indivíduos o mesmo sucesso que obtiveram aqueles que desenvolveram essas características de forma inata. Desse modo, o autor avançou em seus estudos, dedicando-se ao entendimento dessas competências, batizadas de "características do comportamento empreendedor” (Matias \& Martins, 2012; Krüger, Pinheiro \& Minello, 2017).

Essas características do comportamento empreendedor foram posteriormente agrupadas em 3 grandes categorias (realização, planejamento e poder) e estão descritas no Quadro 2.

Quadro 2-Características do comportamento empreendedor

\begin{tabular}{|l|l|l|}
\hline Cat. & Caracter. & \multicolumn{1}{c|}{ Comportamentos } \\
\hline \multirow{7}{*}{$\begin{array}{l}\text { Busca de } \\
\text { oportunidades } \\
\text { e iniciativa }\end{array}$} & $\begin{array}{l}\text { Faz as coisas antes de solicitado, ou antes de forçado pelas circunstâncias; age para } \\
\text { expandir o negócio a novas áreas, produtos ou serviços; aproveita oportunidades fora } \\
\text { do comum para começar um negócio, obter financiamentos, equipamentos, terrenos, } \\
\text { local de trabalho ou assistência. }\end{array}$ \\
\cline { 2 - 3 } & $\begin{array}{l}\text { Correr riscos } \\
\text { calculados }\end{array}$ & $\begin{array}{l}\text { Avalia alternativa e calcula riscos deliberadamente; age para reduzir os riscos ou } \\
\text { controlar os resultados; coloca-se em situações que implicam desafios ou riscos } \\
\text { moderados. }\end{array}$ \\
\cline { 2 - 4 } & Persistência & $\begin{array}{l}\text { Age diante de um obstáculo significativo; age repetidamente ou muda de estratégia, a } \\
\text { fim de enfrentar um desafio ou superar um obstáculo; } \\
\text { faz um sacrifício pessoal ou desenvolve um esforço extraordinário para completar uma } \\
\text { tarefa. }\end{array}$ \\
\cline { 2 - 4 } & $\begin{array}{l}\text { Exigência de } \\
\text { qualidade e } \\
\text { eficiência }\end{array}$ & $\begin{array}{l}\text { Encontra maneiras de fazer as coisas melhor, mais rápido ou mais barato; } \\
\text { age de maneira a fazer coisas que satisfazem ou excedem padrões de excelência; } \\
\text { desenvolve ou utiliza procedimentos para assegurar que o trabalho seja terminado a } \\
\text { tempo ou que o trabalho atenda a padrões de qualidade previamente combinados. }\end{array}$ \\
\cline { 2 - 3 } & $\begin{array}{l}\text { Comprome- } \\
\text { timento }\end{array}$ & $\begin{array}{l}\text { Assume responsabilidade pessoal pelo desempenho necessário ao atingimento de metas } \\
\text { e objetivos; colabora com os empregados ou se coloca no lugar deles, se necessário, } \\
\text { para terminar um trabalho; esmera-se em manter os clientes satisfeitos e coloca em } \\
\text { primeiro lugar a boa vontade a longo prazo, acima do lucro a curto prazo. }\end{array}$ \\
\hline
\end{tabular}




\begin{tabular}{|c|c|c|}
\hline \multirow{3}{*}{ 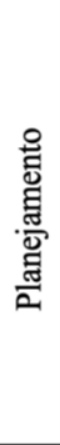 } & $\begin{array}{l}\text { Busca de } \\
\text { informações }\end{array}$ & $\begin{array}{l}\text { Dedica-se pessoalmente a obter informações de clientes, fornecedores e concorrentes; } \\
\text { investiga pessoalmente como fabricar um produto ou fornecer um serviço; consulta } \\
\text { especialistas para obter assessoria técnica ou comercial. }\end{array}$ \\
\hline & $\begin{array}{l}\text { Estabeleci- } \\
\text { mento de } \\
\text { metas }\end{array}$ & $\begin{array}{l}\text { Estabelece metas e objetivos que são desafiantes e que têm significado pessoal; define } \\
\text { metas de longo prazo, claras e específicas; estabelece objetivos mensuráveis e de curto } \\
\text { prazo. }\end{array}$ \\
\hline & $\begin{array}{l}\text { Planejamento } \\
\text { e monitora- } \\
\text { mento sis- } \\
\text { temáticos }\end{array}$ & $\begin{array}{l}\text { Planeja dividindo tarefas de grande porte em sub-tarefas com prazos definidos; } \\
\text { constantemente revisa seus planos, levando em conta os resultados obtidos e mudanças } \\
\text { circunstanciais; } \\
\text { mantém registros financeiros e os utiliza para tomar decisões. }\end{array}$ \\
\hline \multirow{2}{*}{ 苛 } & $\begin{array}{l}\text { Persuasão e } \\
\text { redes de } \\
\text { contato }\end{array}$ & $\begin{array}{l}\text { Utiliza estratégias deliberadas para influenciar ou persuadir os outros; } \\
\text { utiliza pessoas-chave como agentes para atingir seus próprios objetivos; } \\
\text { age para desenvolver e manter relações comerciais. }\end{array}$ \\
\hline & $\begin{array}{l}\text { Indepen- } \\
\text { dência e } \\
\text { autoconfiança }\end{array}$ & $\begin{array}{l}\text { Busca autonomia em relação a normas e controles de outros; mantém seu ponto de } \\
\text { vista mesmo diante da oposição ou de resultados inicialmente desanimadores; expressa } \\
\text { confiança na sua própria capacidade de completar uma tarefa dificil ou de enfrentar um } \\
\text { desafio. }\end{array}$ \\
\hline
\end{tabular}

Fonte: adaptado de MSI (1990).

Estas características do comportamento empreendedor identificadas e descritas por McClelland (Mansfield et al., 1987; MSI, 1990) serão utilizadas para a análise dos dados da pesquisa, como será detalhado a seguir.

Descrita a natureza empreendedora e como ela se manifesta no ser empreendedor, por meio da sua mentalidade e do seu comportamento, passe-se na sessão seguinte aos procedimentos metodológicos adotados nesta pesquisa.

\section{Procedimentos metodológicos}

Esta sessão apresenta os procedimentos metodológicos adotados para o desenvolvimento do estudo. São descritas as abordagens qualitativa e quantitativa, com suas respectivas particularidades, e, ao final, a triangulação dos dados a partir das duas abordagens. A organização na qual a presente pesquisa foi realizada é a Faculdade Antonio Meneghetti (AMF), instituição privada de ensino superior (IES) localizada em Restinga Seca, na região central do Rio Grande do Sul, e que possui ações e projetos de educação empreendedora, de acordo com o conceito de universidade empreendedora (Guaranys, 2010).

\section{Abordagem qualitativa}

A abordagem qualitativa da pesquisa foi desenvolvida em três momentos. No primeiro momento, foi realizada uma pesquisa informal (Triviños, 2008; Yin, 2016) com os alunos, a fim de identificar os docentes que, na visão dos alunos, realizam atividades singulares e inovadoras. A pesquisa informal buscou identificar quem são os docentes que as adotam, o que fazem e os resultados alcançados. A partir desse levantamento informal se procedeu ao segundo momento, utilizando como unidades de análise os docentes mais citados pelos discentes. O instrumento de coleta de dados utilizado nesta etapa foram entrevistas semiestruturadas (Minayo, 2018). Após a coleta dos dados, o instrumento de análise adotado foi a análise de conteúdo categorial e de enunciação (Bardin, 2011), com definição de categorias não a priori. Por fim, realizou-se uma análise associativa dos resultados provenientes da investigação realizada com os alunos e com os professores.

Os sujeitos da pesquisa informal foram alunos de graduação da IES investigada. Estipulou-se como meta entrevistar 40\% dos alunos de cada um dos três cursos existentes (Administração, Direito e Sistemas de Informação), conforme foram encontrados circulando pela instituição, seja nos intervalos das aulas, corredores e cafeteria. Dos 427 alunos de graduação da IES, 170 participaram da coleta informal. 
A partir da análise dos dados levantados pela pesquisa informal, foram verificados os quatro docentes mais citados de cada um três dos cursos e os mesmos foram convidados a participar das entrevistas. Dos 52 docentes dos três cursos de graduação, 12 professores participaram das entrevistas, que abordaram a história de vida, a trajetória profissional e diferentes aspectos da educação empreendedora, como a sua visão sobre a docência, as metodologias e práticas pedagógicas adotadas, o papel do aluno no processo de ensino-aprendizagem, e os resultados que têm obtido com os alunos e enquanto professor em relação ao desenvolvimento de características comportamentais e mentalidade empreendedoras. As entrevistas foram gravadas e transcritas e os dados coletados foram analisados com a técnica da análise de conteúdo (Bardin, 2011). Para a definição das categorias não a priori utilizou-se a técnica de enunciação, resultando em seis categorias de análise.

A Figura 1 a seguir apresenta de modo esquemático os procedimentos metodológicos da pesquisa em relação à abordagem qualitativa.

Figura 1 - Procedimentos metodológicos da pesquisa - abordagem qualitativa

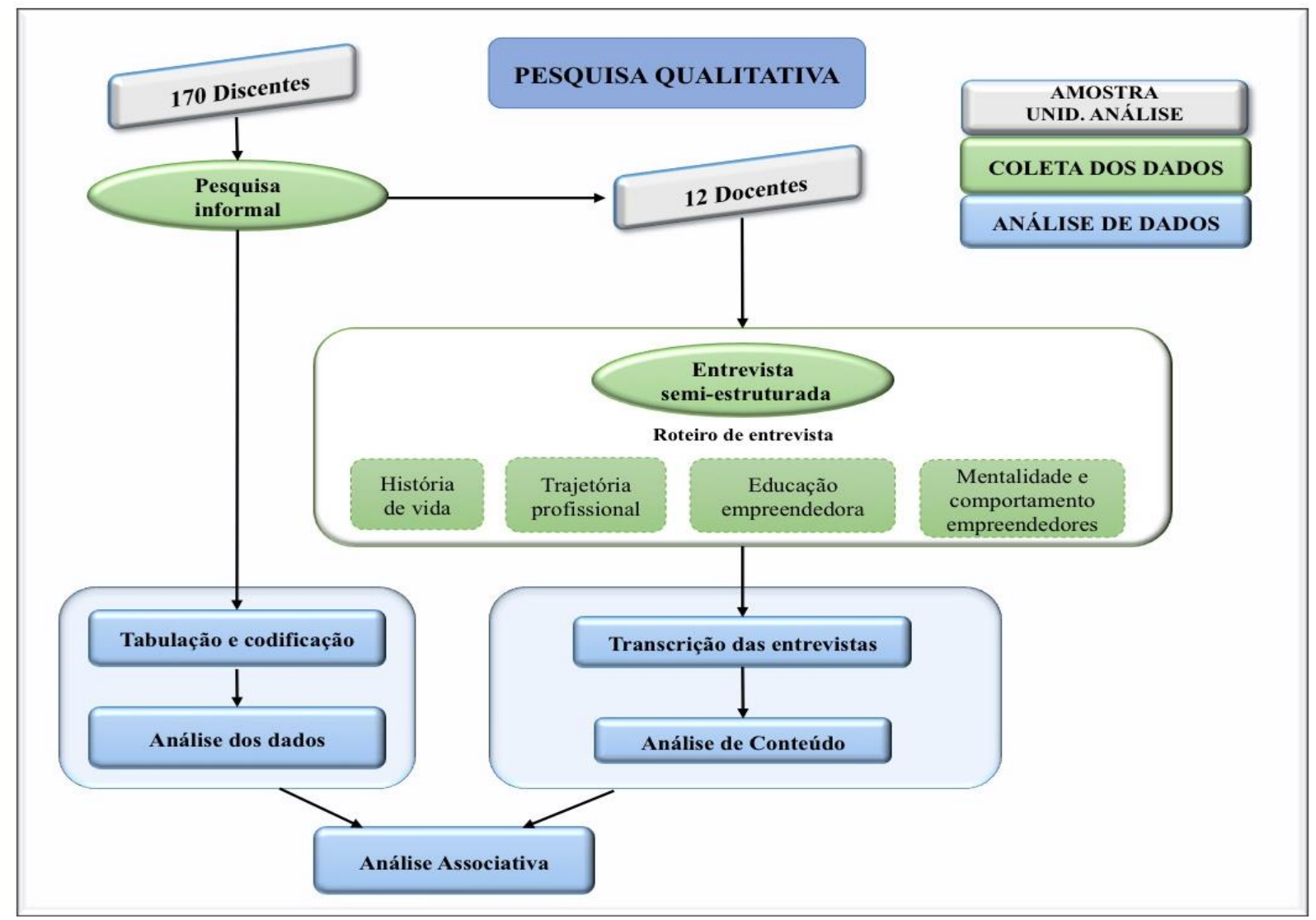

Fonte: elaborado pelos autores.

\section{Abordagem quantitativa}

O processo metodológico da abordagem quantitativa adotou toda a população de discentes da Antonio Meneghetti Faculdade (AMF) e os 12 docentes selecionados a partir da pesquisa informal. Para atingir ao objetivo proposto, utilizaram-se dois instrumentos de coleta. O primeiro refere-se às características comportamentais empreendedoras (CCE's) de McClelland (Mansfield et al., 1987; MSI, 1990) com o objetivo de identificar as características de discentes e docentes. $O$ segundo corresponde ao questionário Forma mentis (Mencarelli, 2014), que mede 5 dimensões da mentalidade empreendedora.

Para a população dos 427 alunos da IES, calculou-se a amostra mínima com base Hair Jr. et al. (2005), 
na qual se considerou uma amostragem não probabilística por conveniência, levando em consideração a quantidade de variáveis dos instrumentos aplicados. Em relação aos docentes, os questionários foram aplicados nos 12 professores mais citados na pesquisa informal realizada com os alunos.

Para tratamento e análise dos dados foram realizados testes estatísticos, utilizando o software SPSS. Nessa ocasião foram analisados quantitativamente e explorados os dados dos modelos propostos por McClelland (Mansfield et al., 1987; MSI, 1990) e Mencarelli (2014).Para cada um dos instrumentos foram calculadas as médias, intensidade e o desvio padrão de cada característica, dimensão e construtos estudados. Em seguida, para estimar a confiabilidade, foi medida a consistência interna através do Coeficiente Alfa de Cronbach (Sampieri, Collado \& Lucio, 2013).

Com a finalidade de estabelecer a relação entre as características comportamentais empreendedoras e as dimensões da mentalidade empreendedora, utilizou-se o Coeficiente de Correlação de Pearson, uma técnica paramétrica que indica a medida de força de associação entre duas variáveis (Collis \& Hussey, 2005). Para avaliar a correlação entre os resultados das características comportamentais empreendedoras e das dimensões da mentalidade empreendedora dos docentes e discentes, realizou-se o teste de Mann-Whitney. Esse teste serve para comparar os postos entre os dois grupos, verificando se as duas populações têm a mesma distribuição, indicando igualdade de comportamentos (Lopes, 2016).

A Figura 2 apresenta de modo esquemático os procedimentos metodológicos da pesquisa em relação à abordagem quantitativa.

Figura 2 - Procedimentos metodológicos da pesquisa - abordagem quantitativa

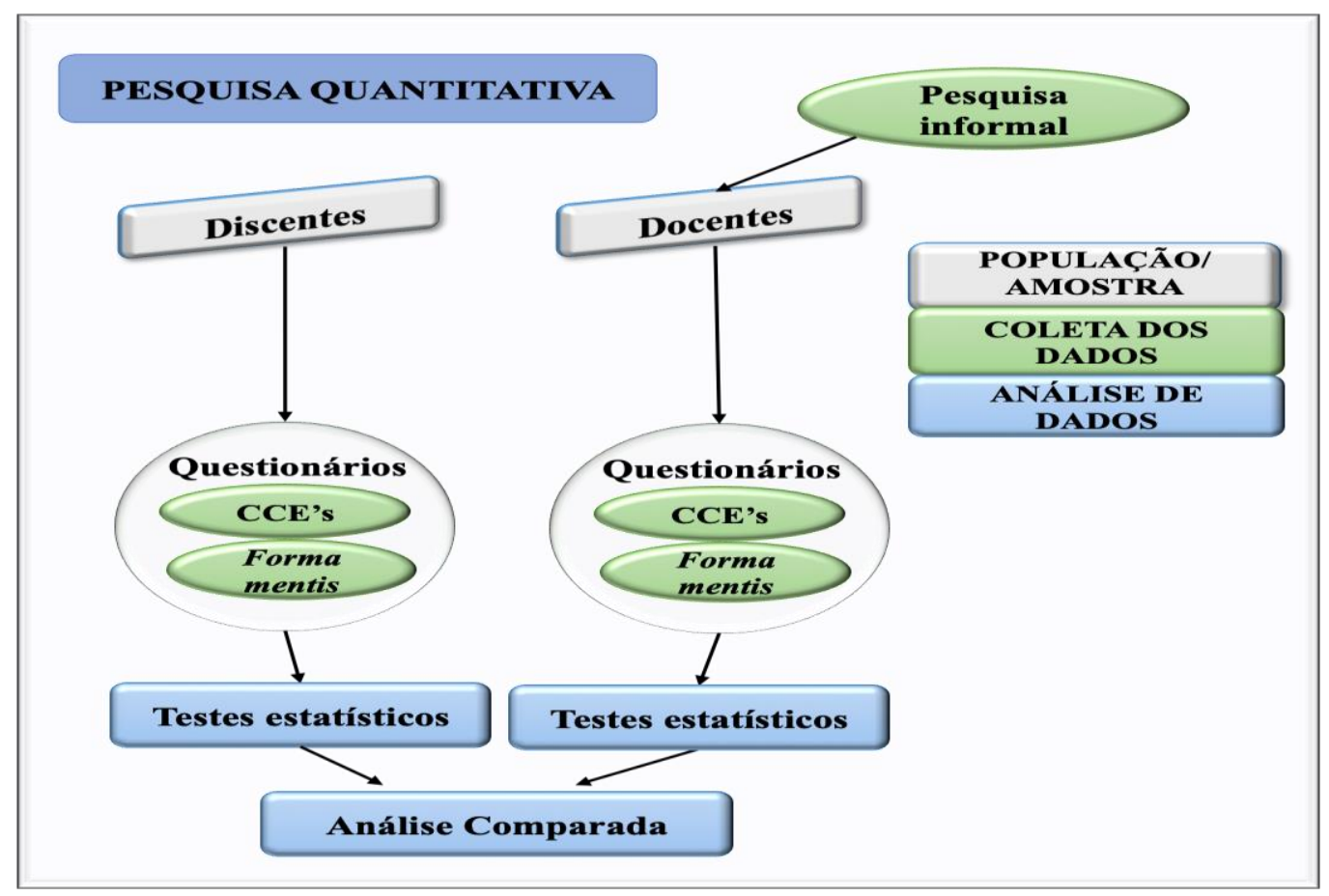

Fonte: elaborado pelos autores.

\section{Triangulação de dados}

O termo triangulação é originário da navegação e da estratégia militar, visando determinar a exata posição de um objeto a partir de diversos pontos de referência. No âmbito das ciências sociais, "a triangulação pode ser definida como uma estratégia de pesquisa baseada na utilização de diversos métodos para investigar um mesmo fenômeno" (Vergara, 2012, p. 242). De forma sucinta, Vergara (2012) afirma que a triangulação pode ser vista a partir de duas óticas: uma que contribui com a 
validade de uma pesquisa, e como uma alternativa para a obtenção de novos conhecimentos, através de novos pontos de vista. Por meio da triangulação podem se estabelecer ligações entre descobertas obtidas pelas diferentes fontes de coleta, ilustrá-las e torná-las mais compreensíveis, conduzindo a paradoxos, proporcionando nova direção aos problemas emergidos no estudo (Denzin, 1978; Sampieri; Collado \& Lucio, 2013).

Para Denzin (1978) e Patton (2002) a triangulação pode ser: das fontes de dados (triangulação de dados); entre os diferentes avaliadores (triangulação do investigador); de perspectivas para o mesmo conjunto de dados (triangulação da teoria); e dos métodos (triangulação metodológica). Na perspectiva deste estudo, utilizou-se a triangulação de dados, que para Patton (2002) é um estudo de combinação de métodos, tanto quantitativos como qualitativos. Morse (1991) também propõe o emprego da expressão "triangulação simultânea" para o uso ao mesmo tempo de métodos quantitativos e qualitativos, como proposto pelo presente estudo.

A Figura 3 seguir, apresenta de modo esquemático como se deu o processo metodológico.

Figura 3 - Síntese do método de pesquisa

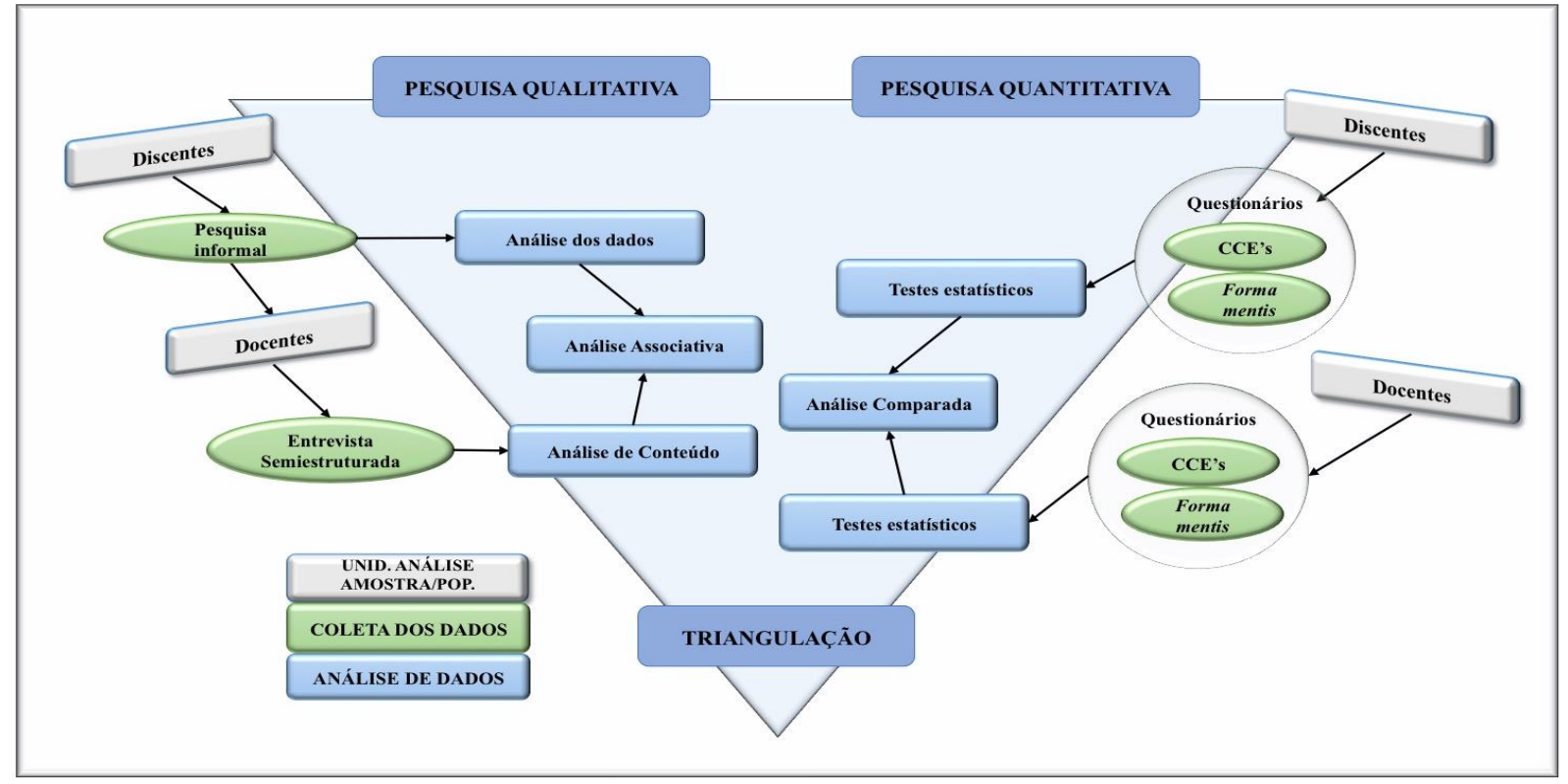

Fonte: elaborado pelos autores.

A partir da fundamentação teórica e dos procedimentos metodológicos descritos anteriormente, analisam-se e descrevem-se a seguir os resultados alcançados com a pesquisa.

\section{Apresentação e análise dos resultados}

Da população de 427 alunos foram obtidos 261 questionários nos três cursos de graduação da IES, dos quais foram desconsiderados 12 instrumentos que foram respondidos de modo incompleto. $\mathrm{O}$ percentual de respondentes por cursos é apresentado na Tabela 1. 
Tabela 1 - Totais de respondentes - alunos

\begin{tabular}{c|c|c|c}
\hline Curso & Total de alunos & Respondentes & $\mathbf{\%}$ \\
\hline Administração & 137 & 94 & 68,6 \\
\hline Sistemas de informação & 73 & 45 & 61,6 \\
\hline Direito & 217 & 110 & 50,7 \\
\hline Totais & $\mathbf{4 2 7}$ & $\mathbf{2 4 9}$ & $\mathbf{5 8 , 3}$ \\
\hline
\end{tabular}

Fonte: elaborado pelos autores.

A amostra foi então composta por 249 alunos de graduação, superior à amostra mínima calculada, representando 58,3\% da população. O perfil dos respondentes é apresentado no Quadro 3.

Quadro 3 - Características da amostra - alunos

\begin{tabular}{|c|c|c|c|}
\hline \multirow[t]{2}{*}{ Categoria } & \multirow[t]{2}{*}{ Variáveis } & \multicolumn{2}{|c|}{ Frequência } \\
\hline & & Absoluta & $\%$ \\
\hline \multirow[t]{2}{*}{ Gênero } & Masculino & 131 & 52,82 \\
\hline & Feminino & 117 & 47,18 \\
\hline \multirow[t]{3}{*}{ Estado Civil } & Casado(a) & 17 & 6,94 \\
\hline & Solteiro(a) & 219 & 89,39 \\
\hline & Separado(a) & 9 & 3,67 \\
\hline \multirow[t]{5}{*}{ Ano da faculdade } & $1^{\circ}$ ano & 79 & 31,73 \\
\hline & $2^{\circ}$ ano & 44 & 17,67 \\
\hline & $3^{\circ}$ ano & 51 & 20,48 \\
\hline & $4^{\circ}$ ano & 60 & 24,10 \\
\hline & $5^{\circ}$ ano & 15 & 6,02 \\
\hline \multirow[t]{2}{*}{ Trabalha } & Sim & 212 & 85,48 \\
\hline & Não & 36 & 14,52 \\
\hline \multirow{2}{*}{$\begin{array}{l}\text { Teve formação } \\
\text { empreendedora na graduação }\end{array}$} & Sim & 245 & 98,39 \\
\hline & Não & 4 & 1,61 \\
\hline \multirow{2}{*}{$\begin{array}{l}\text { Possui ou já teve ativ. } \\
\text { empreendedora na família }\end{array}$} & Sim & 191 & 77,96 \\
\hline & Não & 54 & 22,04 \\
\hline Categoria & Parâmetros & \multicolumn{2}{|c|}{ Valores } \\
\hline \multirow[t]{3}{*}{ Idade } & Mínima & \multicolumn{2}{|c|}{17} \\
\hline & Máxima & \multicolumn{2}{|c|}{68} \\
\hline & Média & \multicolumn{2}{|c|}{24,4} \\
\hline
\end{tabular}

Fonte: elaborado pelos autores.

Em relação aos docentes, os instrumentos de coleta adotados por esta pesquisa foram respondidos pelos 12 professores mais referenciados pelos alunos na pesquisa informal, cujo perfil é apresentado no Quadro 4. 
Quadro 4 - Características da amostra - docentes

\begin{tabular}{|c|c|c|c|}
\hline \multirow[t]{2}{*}{ Categoria } & \multirow[t]{2}{*}{ Variáveis } & \multicolumn{2}{|c|}{ Frequência } \\
\hline & & Absoluta & $\%$ \\
\hline \multirow[t]{2}{*}{ Gênero } & Masculino & 8 & 66,67 \\
\hline & Feminino & 4 & 33,33 \\
\hline \multirow[t]{2}{*}{ Estado Civil } & Casado(a) & 4 & 33,33 \\
\hline & Solteiro(a) & 8 & 66,67 \\
\hline \multirow{2}{*}{$\begin{array}{l}\text { Teve formação empreendedora } \\
\text { na graduação }\end{array}$} & Sim & 10 & 83,33 \\
\hline & Não & 2 & 16,67 \\
\hline \multirow{2}{*}{$\begin{array}{l}\text { Possui ou já teve atividade } \\
\text { empreendedora }\end{array}$} & $\mathrm{Sim}$ & 12 & 100,0 \\
\hline & Não & 0 & 0,00 \\
\hline Categoria & Parâmetros & \multicolumn{2}{|c|}{ Valores } \\
\hline \multirow[t]{3}{*}{ Idade } & Mín. & \multicolumn{2}{|c|}{30} \\
\hline & Máx. & \multicolumn{2}{|c|}{44} \\
\hline & Média & \multicolumn{2}{|c|}{35,5} \\
\hline
\end{tabular}

Fonte: elaborado pelos autores.

Tendo em vista os vários instrumentos de coleta e as associações realizadas nas abordagens qualitativa e quantitativa, com posterior triangulação de dados, neste artigo optou-se por apresentar os resultados de modo sintético e esquemático, a partir de cada objetivo específico traçado para a pesquisa.

\section{Características comportamentais e mentalidade empreendedora nos docentes e discentes}

Em relação ao primeiro objetivo específico (identificar as dimensões da mentalidade e as características do comportamento empreendedor de alunos de graduação e de docentes de diferentes cursos da instituição de ensino), verificou-se que os docentes pesquisados possuem as 10 características comportamentais empreendedoras definidas por McClelland (MSI, 1990), sendo que 7 delas se configuram como intensidade média (busca de oportunidades e iniciativa, comprometimento, exigência de qualidade e eficiência, estabelecimento de metas, busca de informações, planejamento e monitoramento sistemático, e independência e autoconfiança) e 3 características possuem intensidade baixa (persistência, correr riscos calculados, e persuasão e rede de contatos). A característica com maior média foi comprometimento e a com menor média foi correr riscos calculados. Estes dados estão no Quadro 5, que traz a análise estatística descrita dos dados coletados com os docentes.

Quadro 5 - Estatística descritiva - características do comportamento empreendedor dos docentes

\begin{tabular}{|c|l|c|c|c|c|}
\hline Instr. & \multicolumn{1}{|c|}{ Dimensão/Característica } & Mín. & Máx. & Média & Desvio Padr. \\
\hline \multirow{8}{*}{} & Busca de oportunidades e iniciativa & 18 & 24 & 20,50000 & 1,93061 \\
\cline { 2 - 6 } & Persistência & 15 & 22 & 17,91667 & 1,83196 \\
\cline { 2 - 6 } & Comprometimento & 19 & 24 & 21,08333 & 1,24011 \\
\cline { 2 - 6 } & Exigência de qualidade e eficiência & 17 & 22 & 20,16667 & 1,74946 \\
\cline { 2 - 6 } & Correr riscos calculados & 15 & 21 & 17,50000 & 1,62369 \\
\cline { 2 - 6 } & Estabelecimento de metas & 16 & 24 & 20,50000 & 2,46798 \\
\cline { 2 - 6 } & Busca de informações & 17 & 25 & 20,91667 & 2,71221 \\
\cline { 2 - 6 } & Planejamento e monitoramento sist. & 17 & 25 & 19,83330 & 2,55248 \\
\cline { 2 - 6 } & Persuasão e rede de contatos & 13 & 23 & 18,08333 & 2,64432 \\
\cline { 2 - 6 } & Independência e autoconfiança & 17 & 22 & 19,58333 & 1,72986 \\
\hline
\end{tabular}

Fonte: elaborado pelos autores.

Utilizando a pontuação mínima de 15 pontos, todos os docentes investigados nesta pesquisa podem ser considerados empreendedores segundo o questionário das CCE's (Mansfield et al., 1987), conforme se verifica na Figura 4. 
Figura 4 - Distribuição das médias das características comportamentais empreendedoras - docentes

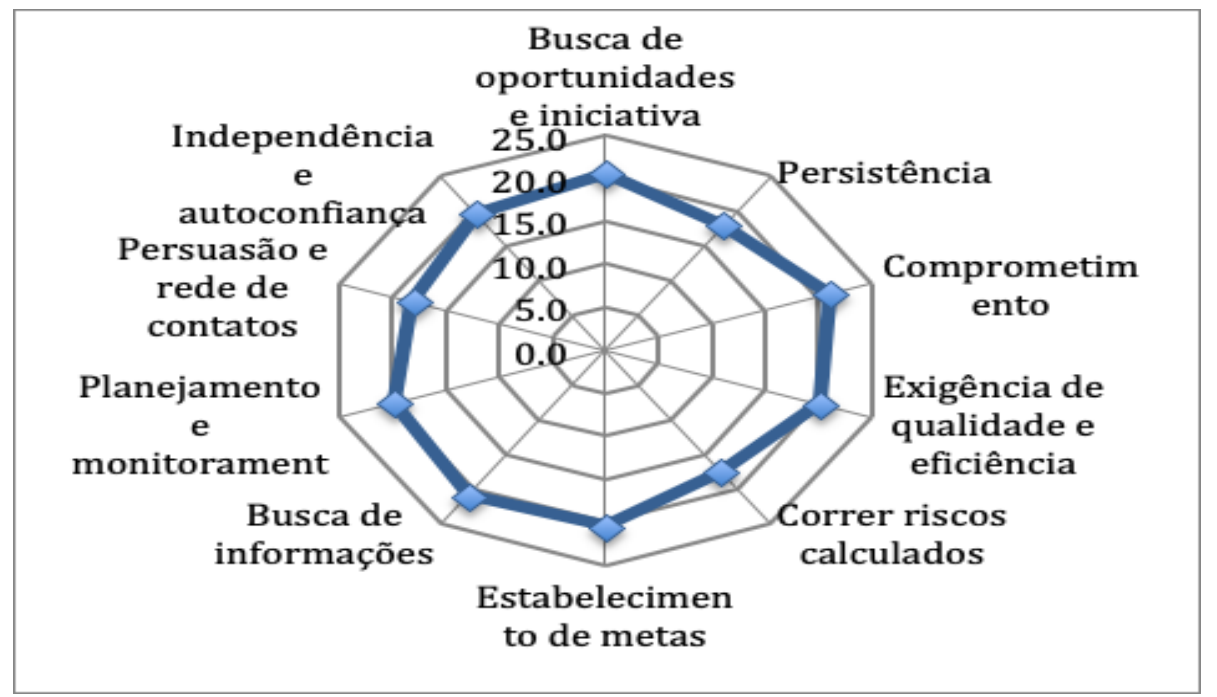

Fonte: elaborado pelos autores.

No entanto, para o presente estudo, optou-se por adotar uma estratificação para analisar a intensidade das CCE's dos participantes, com o objetivo de melhor compreender as suas características. Adotou-se assim uma estratificação que divide a pontuação total, classificando-a em níveis de intensidade: Característica Inexistente, Baixo, Alto e Muito Alto. Para melhor visualização dos dados com essa estratificação, utiliza-se uma escala complementar de cores da seguinte forma: Característica Inexistente abaixo de 15 pontos (vermelho), Baixo de 15 a 18,3 pontos (laranja), Médio de 18,4 a 21,7 pontos (amarelo), e Alto de 21,7 a 25 pontos (verde), o que pode ser verificado na Figura 5 a seguir.

Figura 5 - Estratificação dos níveis de CCE’s

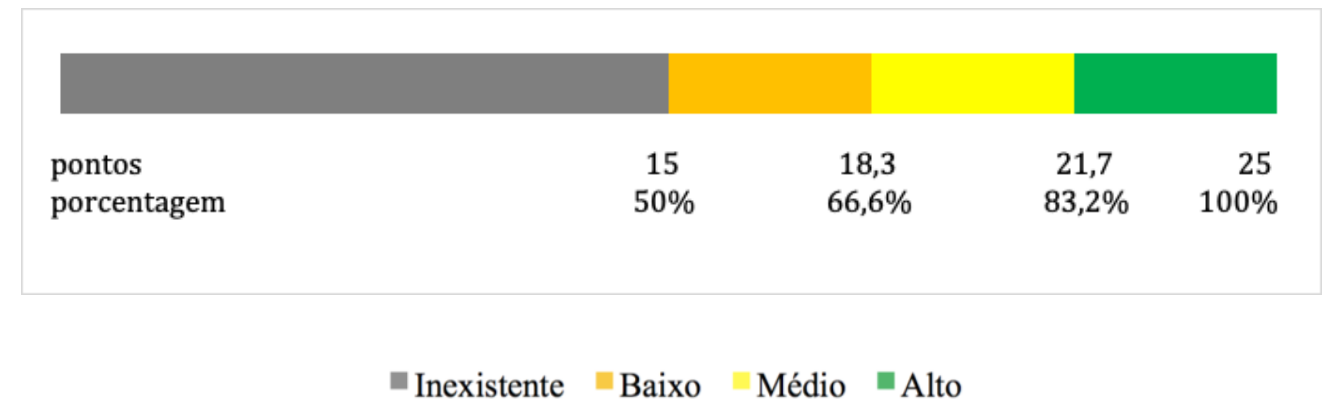

Fonte: elaborado pelos autores.

A partir desta escala criada, a Figura 6 apresenta as médias de cada dimensão das características comportamentais empreendedoras verificadas nos docentes. 
Figura 6 - Média das características comportamentais empreendedoras - docentes

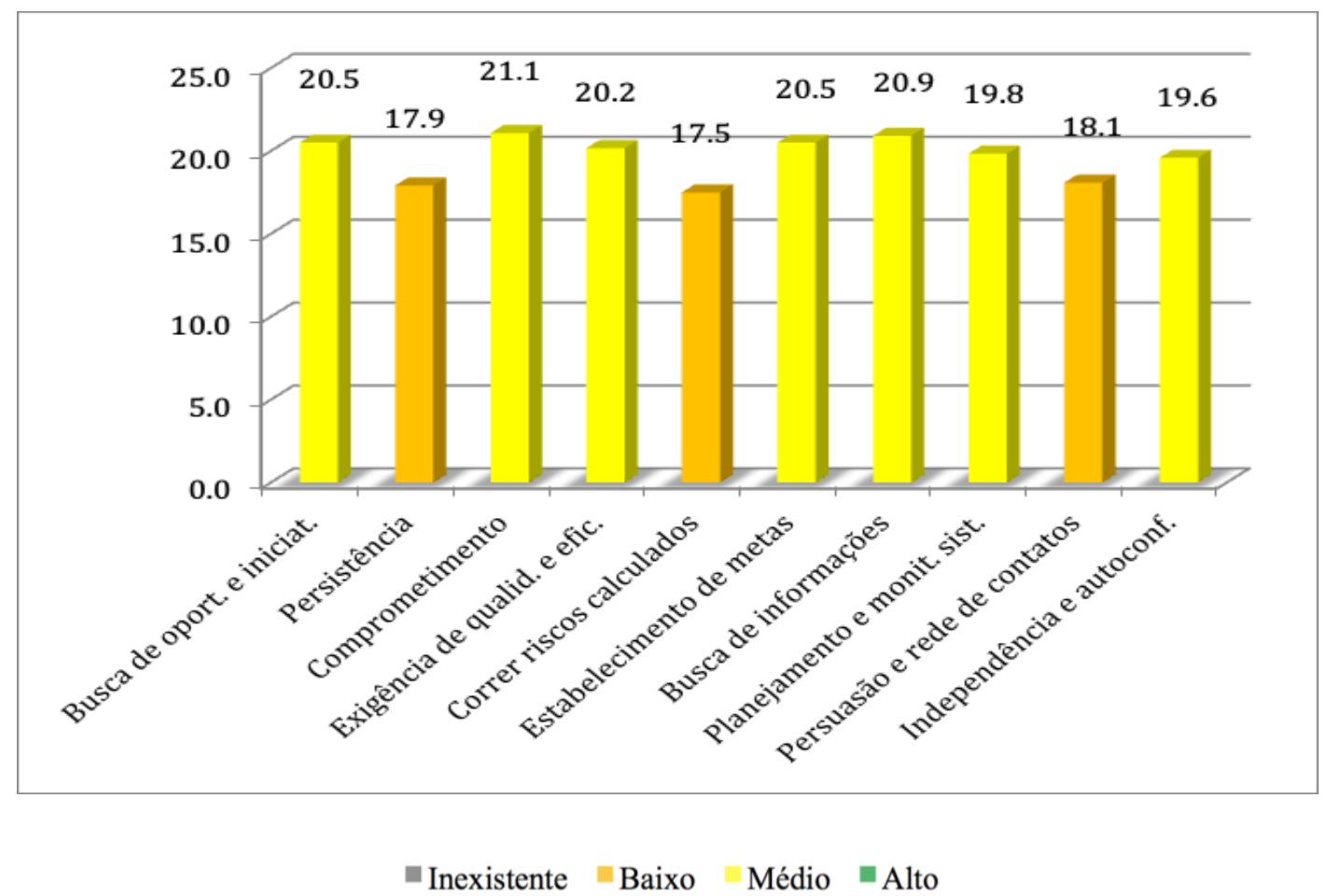

Fonte: elaborado pelos autores.

Em relação aos discentes, 6 características comportamentais apresentaram médias com intensidade média (busca de oportunidades e iniciativa, comprometimento, estabelecimento de metas, exigência de qualidade e eficiência, busca de informações, e independência e autoconfiança) e 4 características apresentaram médias baixas (persistência, correr riscos calculados, planejamento e monitoramento sistemático, e persuasão e rede de contatos). A característica com maior média foi estabelecimento de metas e a menor média foi obtida correr riscos calculados. A estatística descritiva deste dados estão descritos no Quadro 6.

Quadro 6 - Estatística descritiva - características do comportamento empreendedor dos discentes

\begin{tabular}{|l|l|c|c|c|c|}
\hline Instr. & \multicolumn{1}{|c|}{ Dimensão/Característica } & Mín. & Máx. & Média & Desvio Padr. \\
\hline \multirow{4}{*}{} & Busca de oportunidades e iniciativa & 13 & 25 & 19,27711 & 1,98774 \\
\cline { 2 - 6 } & Persistência & 10 & 23 & 17,59438 & 2,008 \\
\cline { 2 - 6 } & Comprometimento & 12 & 25 & 20,40161 & 2,36049 \\
\cline { 2 - 6 } & Exigência de qualidade e eficiência & 8 & 25 & 19,00803 & 2,91823 \\
\cline { 2 - 6 } & Correr riscos calculados & 9 & 23 & 16,92771 & 2,37824 \\
\cline { 2 - 6 } & Estabelecimento de metas & 13 & 25 & 20,63454 & 2,44103 \\
\cline { 2 - 6 } & Busca de informações & 10 & 25 & 19,51406 & 2,73287 \\
\cline { 2 - 6 } & Planejamento e monitoramento sist. & 10 & 25 & 18,06024 & 2,45943 \\
\cline { 2 - 6 } & Persuasão e rede de contatos & 10 & 25 & 17,91165 & 2,46758 \\
\cline { 2 - 6 } & Independência e autoconfiança & 12 & 25 & 19,4739 & 2,25589 \\
\hline
\end{tabular}

Fonte: elaborado pelos autores. 
Utilizando a pontuação mínima de 15 pontos, todos os alunos investigados nesta pesquisa também podem ser considerados empreendedores segundo o questionário das CCE’s (Mansfield et al., 1987), conforme se verifica na Figura 7.

Figura 7 - Distribuição das médias das características comportamentais empreendedoras - discentes

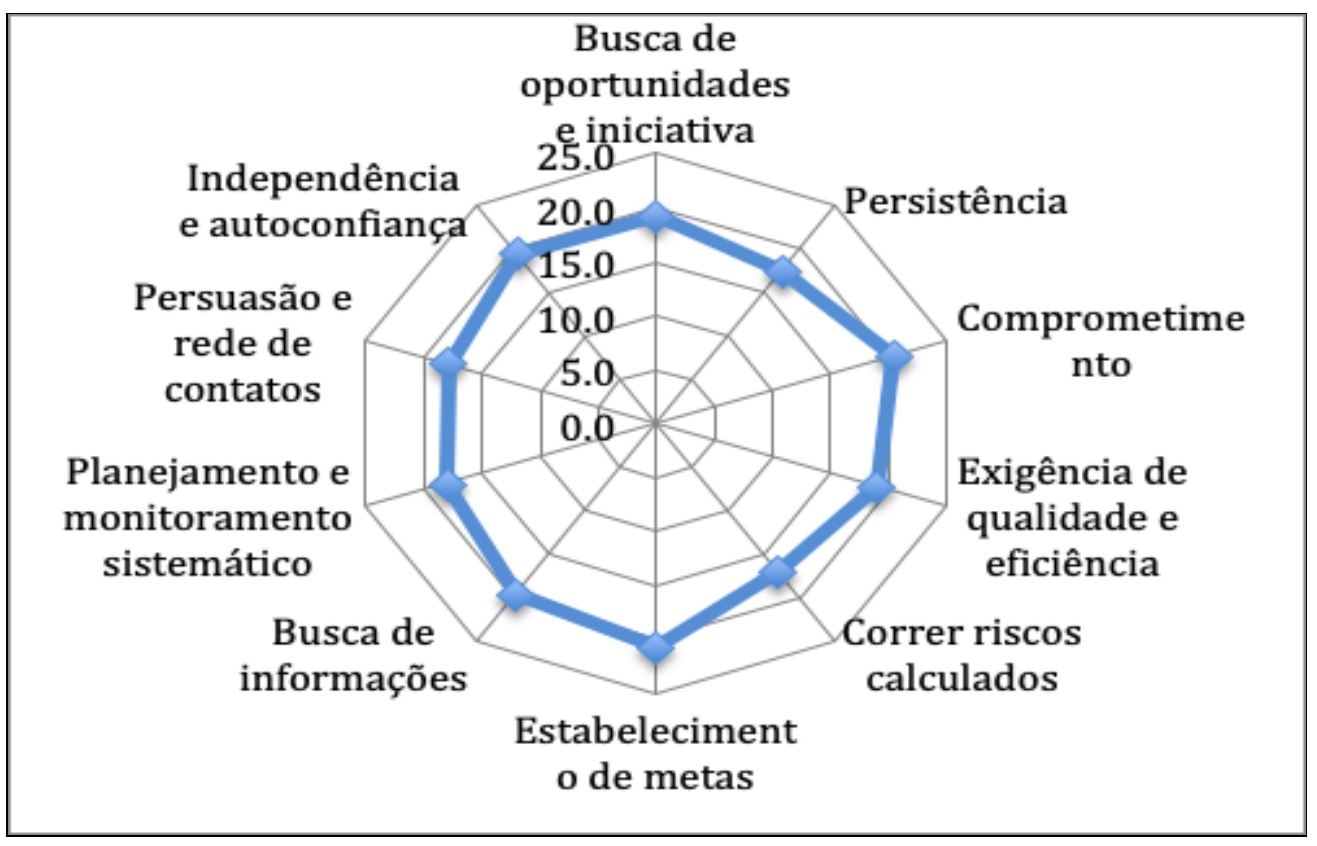

Fonte: elaborado pelos autores.

$\mathrm{Na}$ Figura 8 podem-se consultar as médias de cada dimensão das características comportamentais empreendedoras dos docentes, utilizando a estratificação por intensidades adotada anteriormente.

Figura 8 - Média das características comportamentais empreendedoras - discentes

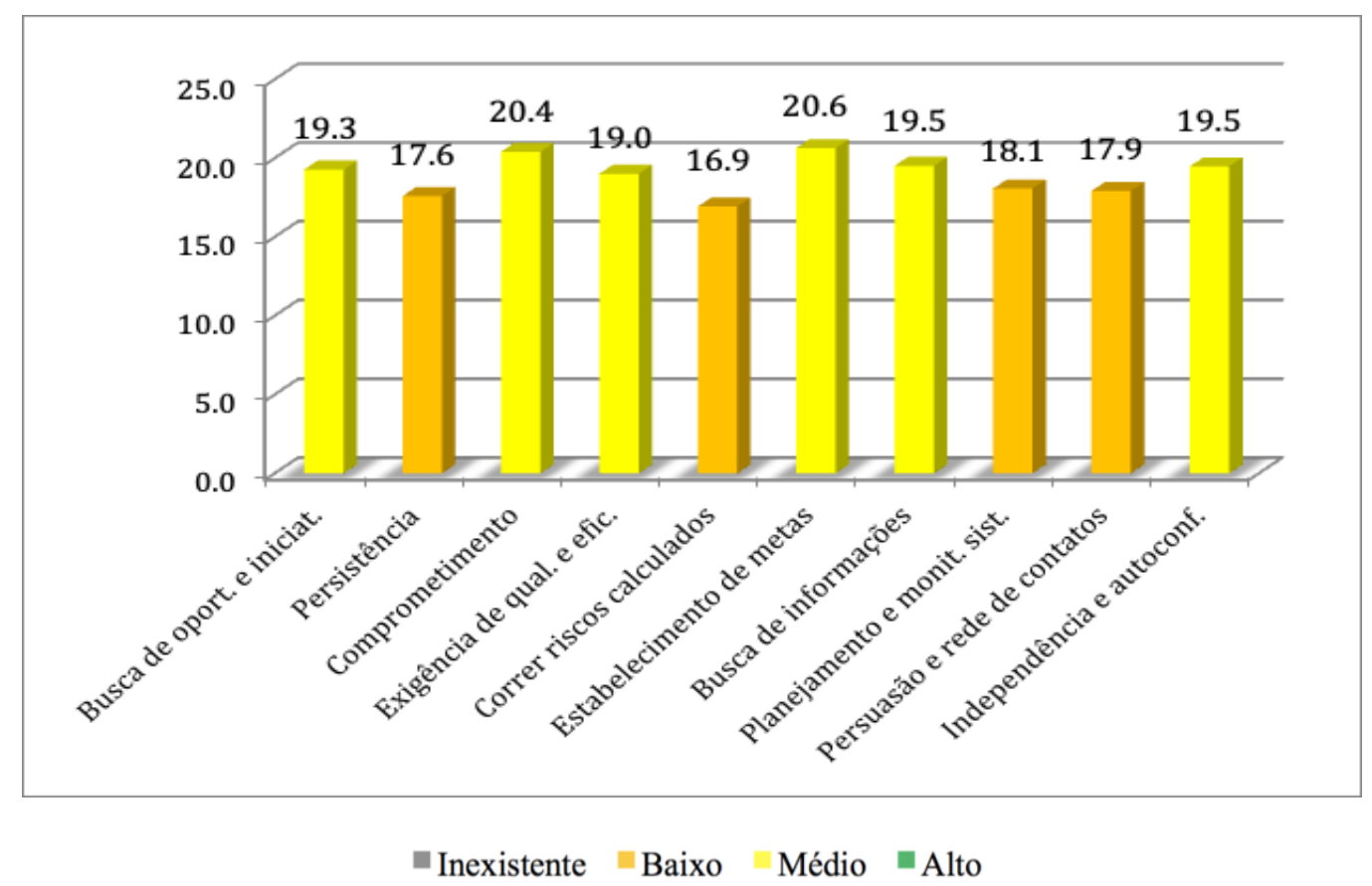

Fonte: elaborado pelos autores. 
Em relação à mentalidade empreendedora dos docentes investigados, a maior média proporcional entre as dimensões da mentalidade é a responsabilidade, e a menor o espírito de iniciativa e resolução de problemas. Das médias das 5 dimensões, 4 delas apresentam intensidade alta (autonomia, responsabilidade, vontade e capacidade de gerir relações funcionais) e uma delas, espírito de iniciativa e resolução de problemas, apresenta intensidade média, conforme pode ser visualizado no Quadro 7 a seguir.

Quadro 7 - Estatística descritiva - características do comportamento empreendedor dos docentes

\begin{tabular}{|c|l|c|c|c|c|}
\hline Instr. & \multicolumn{1}{|c|}{ Dimensão/Característica } & Mín. & Máx. & Média & Desvio Padr. \\
\hline \multirow{2}{*}{$*$} & Autonomia & 8 & 13 & 9,91667 & 1,24011 \\
\cline { 2 - 6 } & Responsabilidade & 9 & 16 & 13,83333 & 1,94625 \\
\cline { 2 - 6 } & Vontade & 7 & 12 & 9,66667 & 1,49747 \\
\cline { 2 - 6 } & Espírito de iniciativa e resolução probl. & 7 & 11 & 8,66667 & 1,43548 \\
\cline { 2 - 6 } & Relações funcionais com o grupo & 3 & 8 & 5,75000 & 1,42223 \\
\hline
\end{tabular}

Fonte: elaborado pelos autores.

A Figura 9 a seguir apresenta as médias de cada dimensão da mentalidade empreendedora dos docentes. Para facilitar a leitura, foi estabelecida uma estratificação por cores, sendo laranja para a intensidade baixa, amarelo para a intensidade média e verde para a intensidade alta.

Figura 9 - Intensidade das médias das dimensões da mentalidade empreendedora - docentes

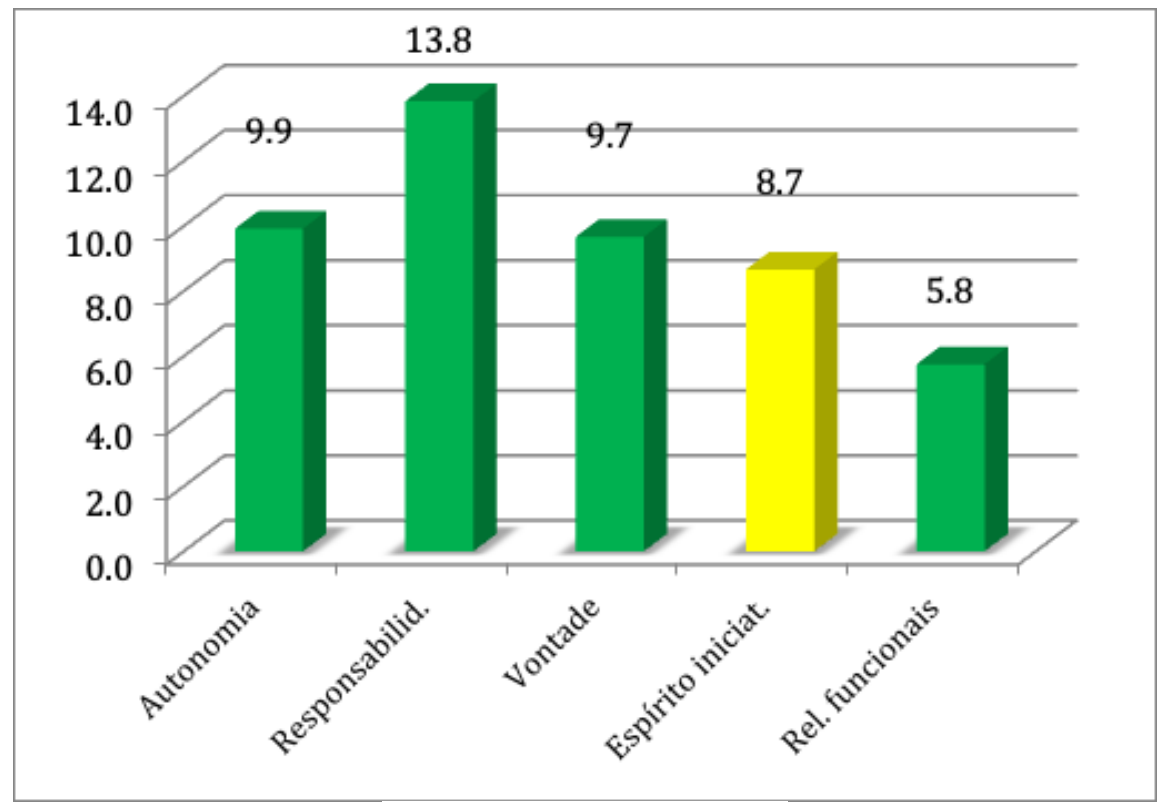

Baixo Médio $\quad$ Alto

Fonte: elaborado pelos autores.

Em relação aos discentes, as maiores médias proporcionais entre as dimensões da mentalidade dos discentes são a responsabilidade e a vontade, e a menor média proporcional é o espírito de iniciativa e resolução de problemas. Todas as 5 dimensões da mentalidade empreendedora dos discentes 
apresentaram médias com intensidade média, conforme descrito no Quadro 8, a seguir.

Quadro 8 - Estatística descritiva - características do comportamento empreendedor dos discentes

\begin{tabular}{|c|l|c|c|c|c|}
\hline Instr. & \multicolumn{1}{|c|}{ Dimensão/Característica } & Mín. & Máx. & Média & Desvio Padr. \\
\hline \multirow{3}{*}{$*$} & Autonomia & 2 & 13 & 8,81526 & 2,47039 \\
\cline { 2 - 6 } & Responsabilidade & 2 & 16 & 10,96787 & 2,9931 \\
\cline { 2 - 6 } & Vontade & 1 & 12 & 8,22892 & 2,46749 \\
\cline { 2 - 6 } & Espírito de iniciativa e resolução probl. & 0 & 12 & 7,80321 & 2,34466 \\
\cline { 2 - 6 } & Relações funcionais com o grupo & 0 & 8 & 5,20482 & 1,66141 \\
\hline
\end{tabular}

Fonte: elaborado pelos autores.

A Figura 10 a seguir apresenta as médias de cada dimensão da mentalidade empreendedora dos docentes, utilizando-se a estratificação por cores.

Figura 10 - Intensidade das médias das dimensões da mentalidade empreendedora - discentes

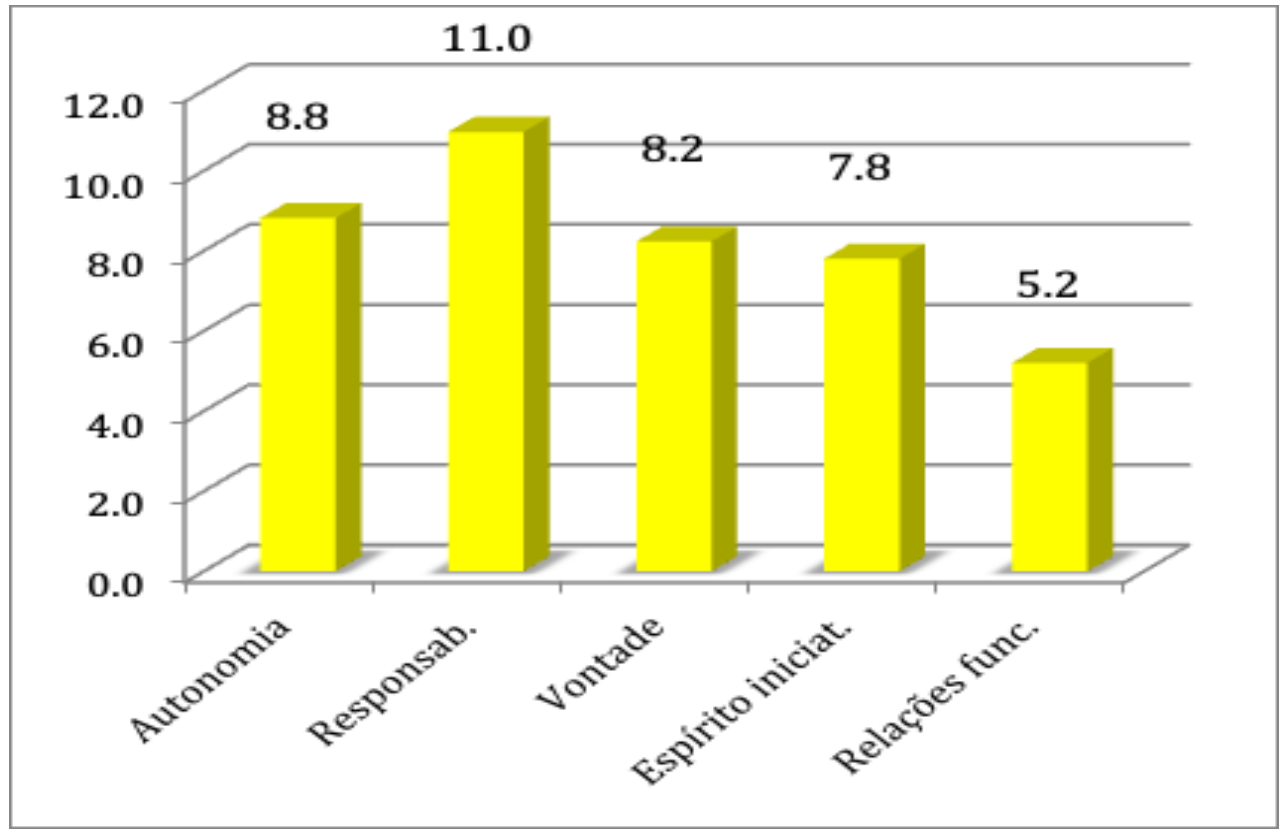

Baixo Médio $=$ Alto

Fonte: elaborado pelos autores.

Comparando os resultados obtidos junto aos docentes e discentes pesquisados, pode-se identificar uma relação entre as suas médias e intensidades das características comportamentais empreendedoras. Os docentes possuem médias um pouco maiores do que os discentes, exceto em relação à característica estabelecimento de metas, cuja média dos discentes é ligeiramente maior. Nas demais características a média dos docentes é maior, com a maior diferença na característica planejamento e monitoramento sistemático. A Figura 11 ilustra esta comparação. 
Figura 11 - Média das características comportamentais empreendedoras - docentes e discentes

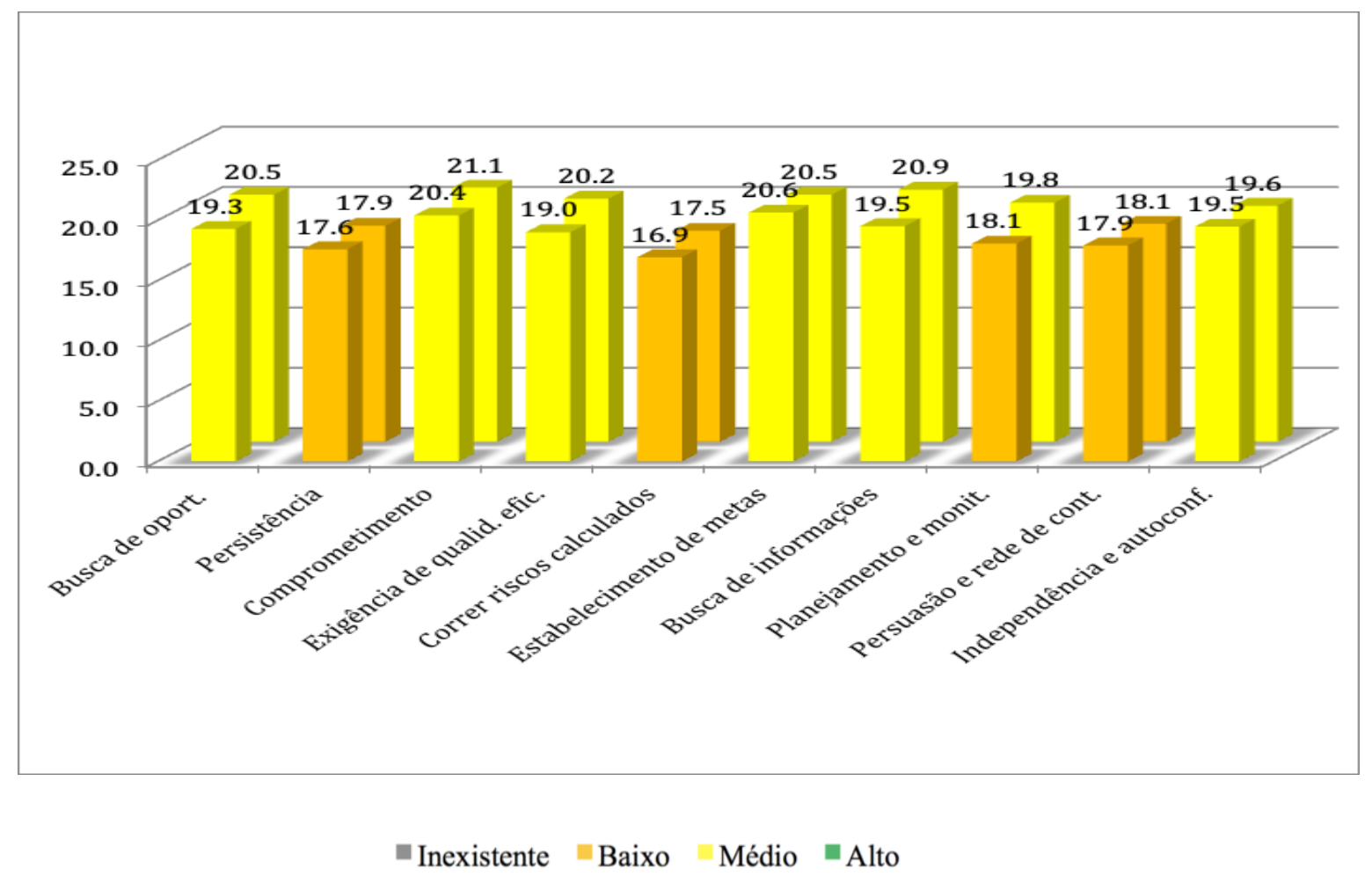

Fonte: elaborado pelos autores.

Assim como nos resultados relativos às características comportamentais empreendedoras, também há certa relação nos resultados da mentalidade empreendedora dos docentes e discentes investigados. A dimensão com a maior diferença é a responsabilidade, com intensidade alta nos docentes e média nos discentes, e a dimensão com os valores mais próximos é espírito de iniciativa e resolução de problemas, com intensidade média tanto nos docentes quanto nos discentes. A Figura 12 ilustra esta comparação.

Figura 12 - Intensidade das médias das dimensões da mentalidade empreendedora - docentes e discentes

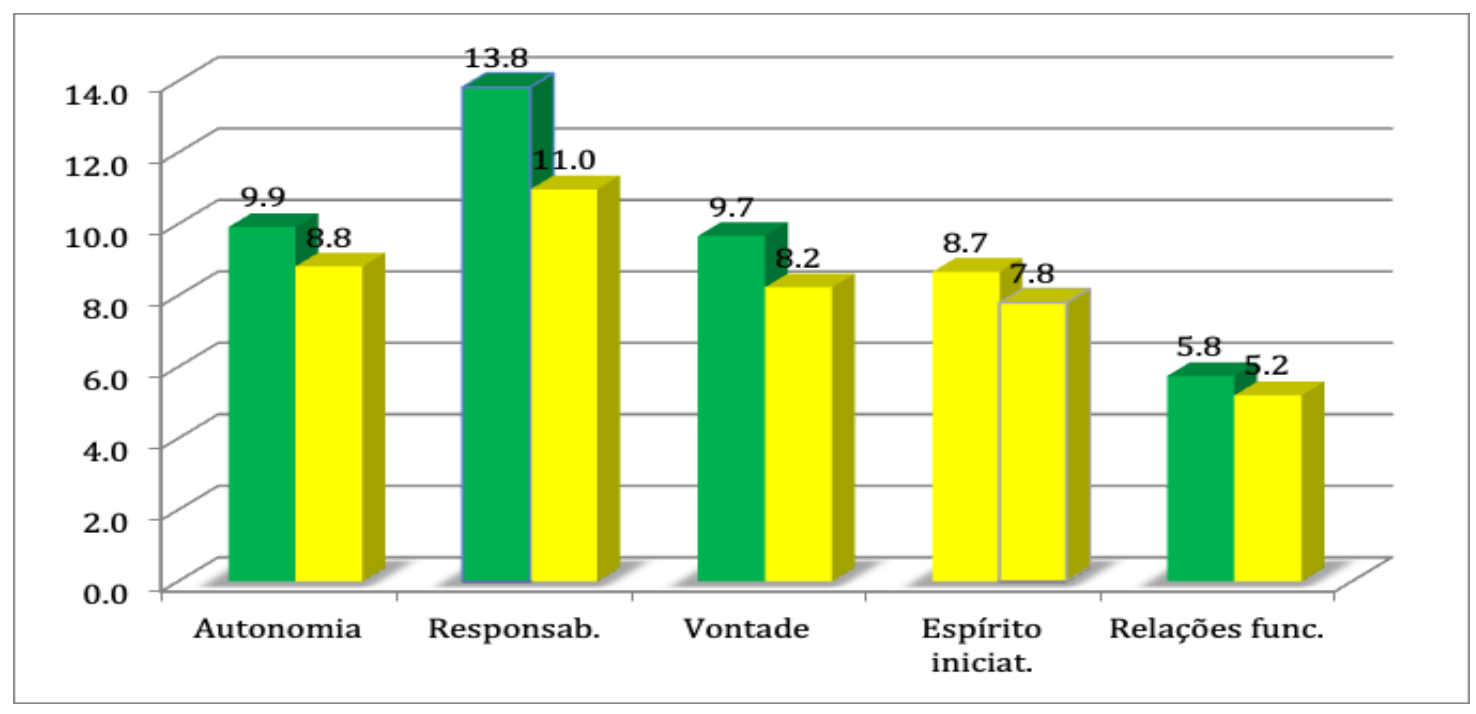

Baixo Médio $\quad$ Alto

Fonte: elaborado pelos autores. 
Ainda que haja essa diferença - esperada tendo em vista que os docentes possuem características empreendedoras e dimensões da mentalidade empreendedora mais fortes do que os discentes, pela atividade que exercem, e considerando também a sua experiência profissional e vivencial maior (Krüger, 2017) - comparando-se as intensidades entre os dois gráficos pode-se identificar uma correlação entre os porcentagens nos docentes e discentes na maior parte das características comportamentais e dimensões da mentalidade.

As novas funções que professor assume na educação empreendedora podem ajudar a explicar essa correlação, tendo em vista que os docentes passam a atuar como um exemplo e estímulo aos alunos, mediando e catalisando o processo de aprendizagem (Lima et. al., 2015a; Silva \& Pena, 2017). Também o aluno assume um novo papel, enquanto responsável pelo próprio aprendizado e desenvolvimento, motivado pelos próprios desejos e anseios que dizem respeito à sua pessoa e ao seu contexto (Schaefer \& Minello, 2016; Wazlawick et. al., 2017). Desenvolve-se assim uma relação dialética e dialógica entre professor e aluno durante o processo de aprendizagem, cujos perfis, modelos de pensamento e de ação se influenciam reciprocamente (Schaefer \& Minello, 2017a).

\section{Relação entre o comportamento empreendedora e a mentalidade empreendedora nos docentes e discentes}

Quanto ao segundo objetivo específico (verificar a relação entre a mentalidade e o comportamento empreendedores em alunos e docentes), inicialmente se analisou a relação entre as características comportamentais $\mathrm{e}$ as dimensões da mentalidade empreendedoras dos docentes e discentes separadamente, utilizando-se o coeficiente de correlação de Pearson. Verificou-se que, nos docentes, as correlações entre as dimensões das características comportamentais empreendedoras e as dimensões da mentalidade empreendedora foram, em sua maioria, associações positivas, de intensidades ínfimas fracas, fracas e moderadas, indicando haver relação direta entre as mesmas, conforme se detalha no Quadro 9 a seguir.

Quadro 9 - Correlação das características comportamentais e mentalidade empreendedoras - docentes

\begin{tabular}{|c|c|c|c|c|c|c|}
\cline { 3 - 7 } \multicolumn{2}{c|}{} & \multicolumn{5}{c|}{ Mentalidade } \\
\cline { 3 - 7 } \multicolumn{2}{c|}{} & Auton. & Respons. & Vontade & Esp. iniciat. & Relações f. \\
\hline \multirow{4}{*}{ Busca de oport. e iniciat. } & 0,1374 & 0,40809 & 0,02257 & 0,55426 & 0,05943 \\
\hline Persistência & 0,36845 & 0,31544 & 0,42967 & 0,39695 & 0,59606 \\
\hline \multirow{4}{*}{ Comprometimento } & 0,60035 & 0,24933 & 0,50111 & 0,58386 & 0,41719 \\
\cline { 2 - 7 } & Exigência qual. eficiência & 0,20796 & 0,38431 & 0,30872 & 0,52196 & 0,56393 \\
\cline { 2 - 7 } & Correr riscos calculados & $-0,05973$ & $-0,28697$ & 0,11445 & $-0,07086$ & 0,18084 \\
\cline { 2 - 7 } & Estabelecimento de metas & $-0,03685$ & 0,22531 & $-0,07867$ & $-0,0717$ & 0,53231 \\
\hline & Busca de informações & 0,1345 & 0,45529 & 0,27613 & 0,22341 & 0,24725 \\
\hline & Planejamento e mon. sist. & $-0,34114$ & $-0,41723$ & $-0,27393$ & $-0,23746$ & $-0,0787$ \\
\hline & Persuasão e rede de cont. & 0,25366 & 0,10008 & 0,19488 & 0,37476 & 0,35748 \\
\cline { 2 - 7 } & Independência e autoconf. & 0,35715 & 0,336 & 0,50199 & 0,02119 & 0,30005 \\
\hline
\end{tabular}

**A correlação é significativa no nível 0,01 (bilateral).

Fonte: elaborado pelos autores.

Em relação aos discentes, verificou-se que as correlações entre as características comportamentais empreendedoras e as dimensões da mentalidade empreendedora foram associações positivas de intensidades ínfimas fracas e fracas, em sua maioria, o que também indica haver relação direta entre as mesmas. O Quadro 10 apresenta estes dados. 
Quadro 10 - Correlação das características comportamentais e atitude empreendedora - discentes

\begin{tabular}{|c|c|c|c|c|c|c|}
\cline { 3 - 7 } \multicolumn{2}{c|}{} & \multicolumn{6}{c|}{ Mentalidade } \\
\cline { 3 - 7 } \multicolumn{2}{c|}{} & Auton. & Respons. & Vontade & Esp. iniciat. & Relações f. \\
\hline \multirow{4}{*}{ Busca de oport. e iniciat. } & 0,20508 & 0,18449 & 0,21392 & 0,17873 & 0,23549 \\
\cline { 2 - 7 } & Persistência & $-0,13547$ & $-0,11153$ & $-0,07477$ & $-0,04357$ & 0,07335 \\
\cline { 2 - 7 } & Comprometimento & 0,22921 & 0,2735 & 0,36699 & 0,32689 & 0,20514 \\
\cline { 2 - 7 } & Exigência qual. eficiência & $-0,07306$ & 0,04112 & 0,04286 & 0,00389 & $-0,0702$ \\
\cline { 2 - 7 } & Correr riscos calculados & $-0,05925$ & 0,0042 & $-0,03427$ & $-0,04667$ & 0,03642 \\
\cline { 2 - 7 } & Estabelecimento de metas & $-0,00857$ & 0,14464 & 0,1157 & 0,01909 & 0,12989 \\
\cline { 2 - 7 } & Busca de informações & 0,00039 & 0,07696 & 0,07217 & 0,0448 & 0,15433 \\
\cline { 2 - 7 } & Planejamento e mon. sist. & 0,05493 & 0,10434 & 0,11267 & 0,11464 & 0,10157 \\
\cline { 2 - 7 } & Persuasão e rede de cont. & $-0,06024$ & $-0,02878$ & 0,00135 & 0,04507 & 0,13131 \\
\cline { 2 - 7 } & Independência e autoconf. & 0,10766 & 0,07333 & 0,12241 & 0,15874 & 0,15259 \\
\hline
\end{tabular}

**A correlação é significativa no nível 0,01 (bilateral).

Fonte: elaborado pelos autores.

Posteriormente, verificou-se a relação entre os resultados das características comportamentais empreendedoras e das dimensões da mentalidade empreendedora dos docentes e discentes, por meio do teste de Mann-Whitney. O Quadro 11 apresenta os resultados do teste de Mann-Whitney dos dados coletados. Quando p > 0,05, pode-se inferir os dois grupos apresentam igualdade de comportamento. A partir dos resultados, pode-se inferir que o grupo de professores e o de alunos possuem igualdade de comportamento em relação à maior parte das características comportamentais empreendedoras e das dimensões da mentalidade empreendedora, conforme ilustra o Quadro 11.

Quadro 11 - Correlação entre as características comportamentais empreendedoras e dimensões da mentalidade empreendedora de docentes e discentes

\begin{tabular}{|c|l|c|}
\hline Instr. & Dimensão/Característica & $\mathbf{p}$ \\
\hline \multirow{4}{*}{} & Busca de oportunidades e iniciativa & 0,0600 \\
\cline { 2 - 3 } & Persistência & 0,5852 \\
\cline { 2 - 3 } & Comprometimento & 0,3692 \\
\cline { 2 - 3 } & Exigência de qualidade e eficiência & 0,1233 \\
\cline { 2 - 3 } & Correr riscos calculados & 0,5512 \\
\cline { 2 - 3 } & Estabelecimento de metas & 0,8839 \\
\cline { 2 - 3 } & Busca de informações & 0,1398 \\
\cline { 2 - 3 } & Planejamento e monitoramento sistemático & 0,0320 \\
\cline { 2 - 3 } & Persuasão e rede de contatos & 0,8174 \\
\cline { 2 - 3 } & Independência e autoconfiança & 0,9590 \\
\hline \multirow{2}{*}{$:$} & Autonomia & 0,1651 \\
\cline { 2 - 3 } & Responsabilidade & 0,0007 \\
\cline { 2 - 3 } & Vontade & 0,0479 \\
\cline { 2 - 3 } & Espírito de iniciativa e resolução de problemas & 0,2218 \\
\cline { 2 - 3 } & Capacidade de gerir relações funcionais & 0,2917 \\
\hline
\end{tabular}

Fonte: elaborado pelos autores. 
Com base em todos esses resultados que buscaram correlacionar as características comportamentais empreendedoras e a mentalidade empreendedora entre os docentes e discentes, em sua maioria indicando uma correlação entre os dois grupos investigados, pode-se inferir que o processo de aprendizagem na educação empreendedora ocorre de maneira complementar entre os professores e alunos investigados.

Leiva, Alegre e Monge (2014) descrevem três modos através dos quais a aprendizagem empreendedora pode ser adquirida: formal, experimental e indireta. A formal se dá por meio da consulta direta a fontes de informação, aulas e processos de treinamento. A experimental a partir da experiência e como ela depois se transforma em conhecimento. E a aquisição indireta ocorre por meio da observação do comportamento e ações de outras pessoas, bem como dos próprios resultados, com aprovação ou desaprovação do contexto e grupo de referência. No caso da graduação, os alunos aprendem através da observação e interação com seus professores, e através dos resultados que alcançam juntos nesse processo. A figura do professor como exemplo de modo de ver as coisas (mentalidade) e de ação (comportamento) tem um efeito indireto, mas determinante, no desenvolvimento das características comportamentais e mentalidade empreendedoras dos alunos (Schaefer \& Minello, 2017a).

Por meio desse processo de aprendizagem, os alunos desenvolvem características comportamentais e de mentalidade junto com seus professores. Esse reconhecimento e alinhamento mútuo é importante pois potencializa os resultados da educação empreendedora (Tschá \& Cruz Neto, 2014), visto que o modo de pensar e de agir dos professores e alunos convergem. A realização de ações e projetos integrados de formação empreendedora (Silva \& Pena, 2017) levam ao desenvolvimento da mentalidade e do comportamento empreendedores tanto dos alunos, quanto dos professores.

\section{Atividades de ensino voltadas à educação empreendedora nos cursos de graduação}

No que se refere ao terceiro objetivo específico (verificar atividades de ensino no processo de educação empreendedora nos cursos de graduação), cruzaram-se os dados da pesquisa informal com a análise de conteúdo das entrevistas, a fim de se verificar convergências ou divergências entre o que os alunos relataram sobre o que e como os docentes realizam em sala de aula, com os relatos dos docentes em relação às suas técnicas didático-pedagógicas e o que buscam desenvolver nos alunos. Verificou-se desse modo que a percepção dos alunos e os relatos dos docentes em relação às atividades realizadas estão diretamente associados, podendo-se inferir que os discentes percebem as atividades realizadas pelos docentes em sala de aula, a sua motivação e objetivos em relação ao processo de ensino e aprendizagem. Esse reconhecimento e alinhamento mútuo é importante pois potencializa os resultados da educação empreendedora, visto que o modo de pensar e de agir dos professores e alunos convergem. O Quadro 12 a seguir ilustra estes resultados, exemplificados com extratos dos dados referentes a 3 docentes. 
Quadro 12 - Associação entre o que os discentes falam (pesquisa informal) e o que os docentes fazem (entrevistas)

\begin{tabular}{|c|c|c|}
\hline Ent. & Percepção dos alunos & $\begin{aligned} \text { Relatos dos docentes } \\
\end{aligned}$ \\
\hline & $\begin{array}{l}\text { Por que indicaria? O que faz de } \\
\text { diferente? }\end{array}$ & $\begin{array}{l}\text { Quais recursos didático-pedagógicos utiliza e o que busca desenvolver nos } \\
\text { alunos? }\end{array}$ \\
\hline E1 & $\begin{array}{l}\text { - Aulas diferenciadas e dinâmicas } \\
\text { - } \quad \text { Aulas fora da sala de aula } \\
\text { - Apresentações sobre o aprendizado } \\
\text { prático do conteúdo } \\
\text { - } \quad \text { Traz exemplos próximos à } \\
\text { realidade } \\
\text { - Estabelecimento de metas para o } \\
\text { semestre } \\
\text { - Uso de vários recursos: filmes, } \\
\text { músicas, dinâmicas } \\
\text { - Domínio da turma } \\
\text { - Leva os alunos a pensarem e } \\
\text { chegarem às respostas por si próprios } \\
\text { - Provoca os alunos a terem várias } \\
\text { percepções das coisas } \\
\text { - Provoca cada um a melhorar } \\
\text { - Foca no desenvolvimento pessoal } \\
\text { junto com o profissional }\end{array}$ & 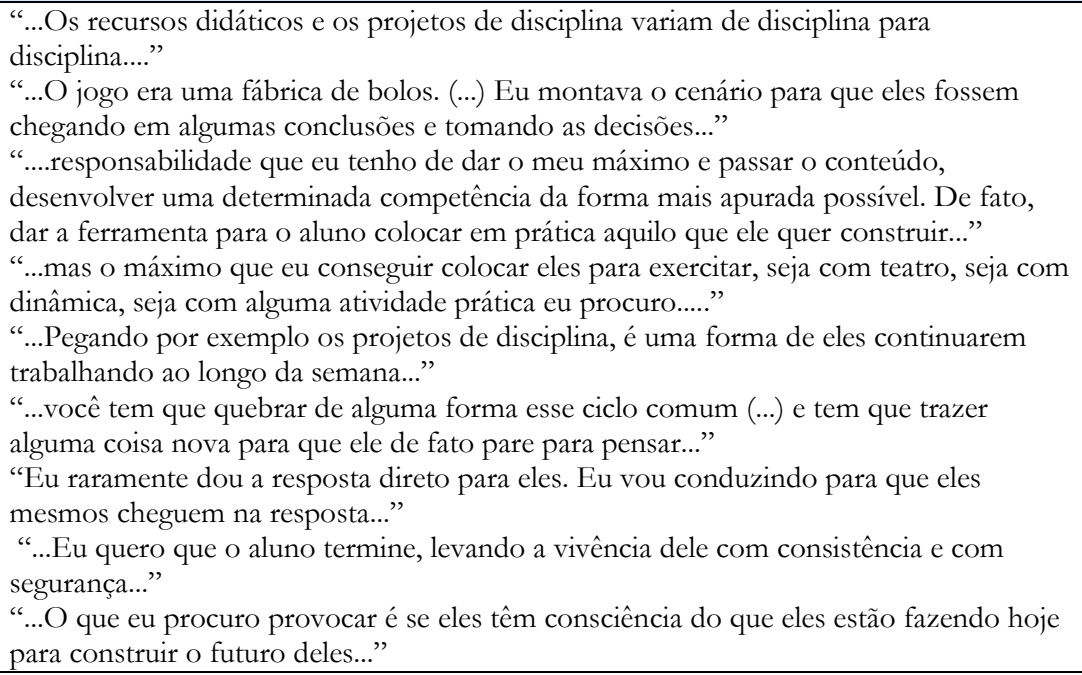 \\
\hline E6 & $\begin{array}{l}\text { - Compartilha experiências da } \\
\text { própria empresa } \\
\text { - } \quad \text { Realiza atividades diferenciadas } \\
\text { - É criativo na hora de passar } \\
\text { trabalhos e atividades } \\
\text { - Domina muito o conteúdo } \\
\text { - } \quad \text { Aulas sempre muito práticas } \\
\text { - Leva a turma à reflexão } \\
\text { - Se sente o prazer dele em ensinar } \\
\text { - Propõe atividades e projetos } \\
\text { desafiadores } \\
\text { - Aulas difíceis, mas muito } \\
\text { interessantes } \\
\text { - Tem como objetivo desenvolver o } \\
\text { aluno tanto no âmbito pessoal como } \\
\text { profissional } \\
\text { - As aulas ajudam a gerir a própria } \\
\text { vida } \\
\text { - Tem muita garra }\end{array}$ & $\begin{array}{l}\text { “...outro modo que eu uso para transmitir essa noção de responsabilidade é a de que } \\
\text { aqui na AMF os professores são empresários ou estão no meio empresarial...” } \\
\text { "....no final, montarmos o sistema para ligar um carro, vendo como funciona, e isso } \\
\text { deixa os alunos entusiasmados, querendo repetir as experiências em casa...” } \\
\text { “...a prioridade, falando na transformação do conhecimento do aluno, é ele entender em } \\
\text { que ele vai utilizar aquilo...” } \\
\text { “...como atividade final, que vá de fato exigir do aluno, colocando ele para se esforçar } \\
\text { de fato, pesquisar muito mais do que o de costume...” } \\
\text { “...são os alunos, é ver que você está levando conhecimento para eles, pois a vida é } \\
\text { medíocre se você faz algo e não agrega valor a ninguém. Então ver que os alunos } \\
\text { gostam da sua aula, não porque você é amigo deles, mas porque eles aprenderam, } \\
\text { saíram melhor, isso é muito gratificante..” } \\
\text { “...se eu fosse definir um valor para um bom aluno seria inquietude. O bom aluno tem } \\
\text { que ser inquieto...” } \\
\text { “...Colocando ele em crise, pois quando você aprende? (...) Se você for pensar nas } \\
\text { nossas vidas, quando tudo está dando certo, você não aprende nada, pois } \\
\text { inconscientemente a pessoa se acomoda na própria mediocridade. Quando se tem uma } \\
\text { crise, a pessoa se obriga a ser muito melhor...” }\end{array}$ \\
\hline E11 & $\begin{array}{l}\text { - } \quad \text { Domínio do conteúdo e clareza na } \\
\text { explicação } \\
\text { - } \quad \text { Dinamismo } \\
\text { - } \quad \text { Muito carismático } \\
\text { - } \quad \text { Ótima didática e cativa os alunos } \\
\text { - } \quad \text { Pelas experiências que tem não só } \\
\text { em sentido técnico, mas também de } \\
\text { vida } \\
\text { - Compreende muito bem a turma e } \\
\text { sabe trabalhar com ela } \\
\text { - Aplica o conteúdo através de } \\
\text { exemplos, demonstrações, práticas } \\
\text { simuladas } \\
\text { - É um professor "parceiro", } \\
\text { também fora da sala de aula } \\
\text { - Aulas bastante práticas } \\
\text { - Como é muito bom no que faz, } \\
\text { inspira a turma a ser melhor } \\
\text { - Compromisso em transformar os } \\
\text { alunos ao longo da faculdade }\end{array}$ & $\begin{array}{l}\text { “...isso é a ideia principal, é que eles saibam se ocupar daquilo que eu estou ensinando } \\
\text { para eles, e não simplesmente repetirem...” } \\
\text { “...a minha ideia, em um primeiro momento, é conquistar a turma, saber quem está na } \\
\text { minha frente, a identidade deles...” } \\
\text { “...Eu vejo muito assim, de você conhecer melhor o aluno e explorar cada um com suas } \\
\text { próprias peculiaridades...” } \\
\text { “...Identificar o perfil da turma, a partir de então criar um espaço que os despertem a } \\
\text { vencer a suas próprias amarras...” } \\
\text { “...Outra atividade é dividir a sala em grupos e levar um caso prático para cada grupo, } \\
\text { pedindo para que eles sustentem uma defesa para o caso. Em uma aula seguinte, os } \\
\text { casos são trocados entre os grupos (...), fazendo com que eles saiam da zona de } \\
\text { conforto...” } \\
\text { "....a nossa relação é uma espécie de pacto, e que só vai funcionar bem se progredirmos } \\
\text { juntos...” } \\
\text { "....existe o momento da técnica, de mostrar o conteúdo, o assunto da aula, e trabalhar } \\
\text { esse conteúdo. Na sequência, eu vou para a prática...” } \\
\text { "...Tenho por desafio instigar aqueles alunos que me parecem mais distantes, aqueles } \\
\text { que inicialmente se mostram mais longe da disciplina....” } \\
\text { “...O básico é para todos, o desenvolvimento das potencialidades é para aqueles que se } \\
\text { descobrem...” } \\
\text { "O fato que me marca é perceber a evolução desses alunos, o interesse e a inteligência } \\
\text { possível...” }\end{array}$ \\
\hline
\end{tabular}

Fonte: elaborado pelos autores com base na pesquisa informal e no relato dos entrevistados. 
A partir da análise de conteúdo das entrevistas realizadas com os docentes, foram definidas seis categorias não a priori: 1. Natureza da educação empreendedora; 2. O papel e função do professor; 3. Novas metodologias e práticas didático-pedagógicas; 4. Educação centrada no aluno; 5. Empreender como forma de ser, saber e fazer; 6. Resultados da educação empreendedora. O Quadro 13 a seguir apresenta cada categoria com os enfoques evidenciados em cada uma delas.

Quadro 12 - Categorias da análise de conteúdo da abordagem qualitativa e respectivos enfoques evidenciados nas entrevistas

\begin{tabular}{|c|c|}
\hline \multirow{4}{*}{$\begin{array}{l}\text { Natureza da } \\
\text { educação } \\
\text { empreendedora }\end{array}$} & Aprendizagem pela ação (aprender fazendo) \\
\hline & Aprendizagem experiencial, contextual e colaborativa \\
\hline & Aplicabilidade prática do conteúdo (elo entre ensino e mundo real) \\
\hline & Formação integrada, transversal e interdisciplinar \\
\hline \multirow{4}{*}{$\begin{array}{l}\text { O papel e função } \\
\text { do professor }\end{array}$} & 0 professor como mediador, facilitador e catalisador \\
\hline & Relação dialética e dialógica entre professor e aluno \\
\hline & Abertura, envolvimento e disponibilidade no processo de ensino \\
\hline & Vocação para a docência \\
\hline \multirow{4}{*}{$\begin{array}{l}\text { Novas } \\
\text { metodologias e } \\
\text { práticas didático- } \\
\text { pedagógicas }\end{array}$} & Técnicas pedagógicas vivenciais, interativas, cooperativas e dinâmicas \\
\hline & Aprendizagem baseada em resolução de problemas e desafios \\
\hline & Projetos, atividades e tarefas que extrapolam a sala de aula \\
\hline & Erros como fonte de aprendizado \\
\hline \multirow{4}{*}{$\begin{array}{l}\text { Educação centrada } \\
\text { no aluno }\end{array}$} & Adequação da formação empreendedora para cada turma \\
\hline & Conhecer o aluno individualmente \\
\hline & A atitude e função do aluno \\
\hline & Motivação do aluno para a educação empreendedora \\
\hline \multirow{4}{*}{$\begin{array}{l}\text { Empreender como } \\
\text { uma forma de ser, } \\
\text { pensar e agir }\end{array}$} & Descoberta e reforço do potencial natural \\
\hline & As dimensões do ser, saber e fazer no empreendedor \\
\hline & Ampliação da visão de mundo e de si mesmo \\
\hline & O protagonismo responsável \\
\hline \multirow{4}{*}{$\begin{array}{l}\text { Resultados da } \\
\text { educação } \\
\text { empreendedora }\end{array}$} & Resultados da educação empreendedora para os alunos \\
\hline & Resultados da educação empreendedora para os professores \\
\hline & Crescimento mútuo, compartilhado e contínuo \\
\hline & Realização como profissional e como pessoa \\
\hline
\end{tabular}

Fonte: elaborado pelos autores.

As quatro primeiras categorias relacionam-se de modo mais direto com o terceiro objetivo específico. Com base nos resultados da análise de conteúdo das entrevistas, pode-se inferir que a educação empreendedora possui uma natureza e especificidades próprias que a diferenciam da educação tradicional, privilegiando a educação pela ação, a aprendizagem experiencial, contextual e colaborativa, na qual os alunos aplicam o conhecimento em situações práticas e reais, buscando resolver problemas e demandas, e aproveitando oportunidades existentes (Lima et. al., 2015a; Schaefer \& Minello, 2017). Essa formação ocorre de modo integrado, transversal e interdisciplinar, extrapolando os limites de uma única disciplina, e oportunizando o elo entre o processo de ensino e o mundo real (Lopes, 2010; Tschá \& Cruz Neto, 2014; Lima et. al., 2014a). 
Nessa proposta, o professor assume um novo papel e novas funções, passando a atuar mais como um mediador, um facilitador e um catalisador do processo de aprendizagem (Dolabela \& Filion, 2013). Para tanto, são necessárias características específicas do docente, ligadas tanto a formação e atuação profissional e prática de mercado, quanto a características comportamentais e de mentalidade empreendedoras, além de uma disponibilidade, abertura e envolvimento, visto que o processo de ensino e aprendizagem transcende os limites espaciais e temporais da sala de aula. Desenvolve-se assim uma relação dialética e dialógica entre os alunos e o professor, o qual deve ter vocação tanto para a atividade docente quanto para a atividade empreendedora, aspecto fundamental para o desenvolvimento das relações positivas e valores relacionados à aprendizagem empreendedora (Nassif et. al, 2009; Rabelo 2010).

Novas metodologias e práticas didático-pedagógicas também são adotadas e desenvolvidas para a educação empreendedora, privilegiando técnicas pedagógicas vivenciais, interativas, cooperativas e dinâmicas (Rocha \& Freitas, 2014; Silva \& Pena, 2017; Araújo \& Davel, 2019). Por meio de projetos, atividades e tarefas práticas, a aprendizagem se desenvolve baseada em resolução de problemas e desafios, e tanto os acertos e conquistas quanto os erros e fracassos se constituem como fontes de aprendizado (Dolabela \& Filion, 2013).

A aprendizagem passa a ser assim centrada no aluno e os conteúdos e recursos didáticos não são mais padronizados e repetidos de turma a turma, mas sim escolhidos e adaptados para a necessidades e objetivos de cada grupo, partindo sempre do indivíduo aluno. Enquanto responsável pelo próprio aprendizado e desenvolvimento, o aluno é motivado pela própria ambição, desejos e anseios que dizem respeito à sua pessoa e ao seu contexto (Henrique \& Cunha, 2008; Chikota; Miranda \& Wazlawick, 2016; Wazlawick et. al., 2017).

\section{Iniciativas de educação empreendedora voltadas ao empreender como uma forma de ser, saber e fazer}

Em relação ao quarto objetivo específico (apurar a contribuição das iniciativas de educação empreendedora para estimular o empreender como uma forma de ser, saber e fazer em alunos e professores), realizou-se a triangulação dos dados das abordagens qualitativa e quantitativa, cruzando-se as expectativas dos alunos em relação à educação empreendedora, identificadas a partir dos relatos da pesquisa informal, com a visão dos professores em relação à formação empreendedora e seu papel como docentes, provenientes da análise de conteúdo das entrevistas, associadas às características comportamentais e mentalidade empreendedoras dos docentes analisadas por meio dos questionários. A Figura 13 ilustra estes resultados de modo esquemático. 
Figura 13 - Associação entre as expectativas dos alunos em relação à formação empreendedora, as características comportamentais e mentalidade empreendedoras docentes e a visão dos professores quanto ao seu papel neste processo.

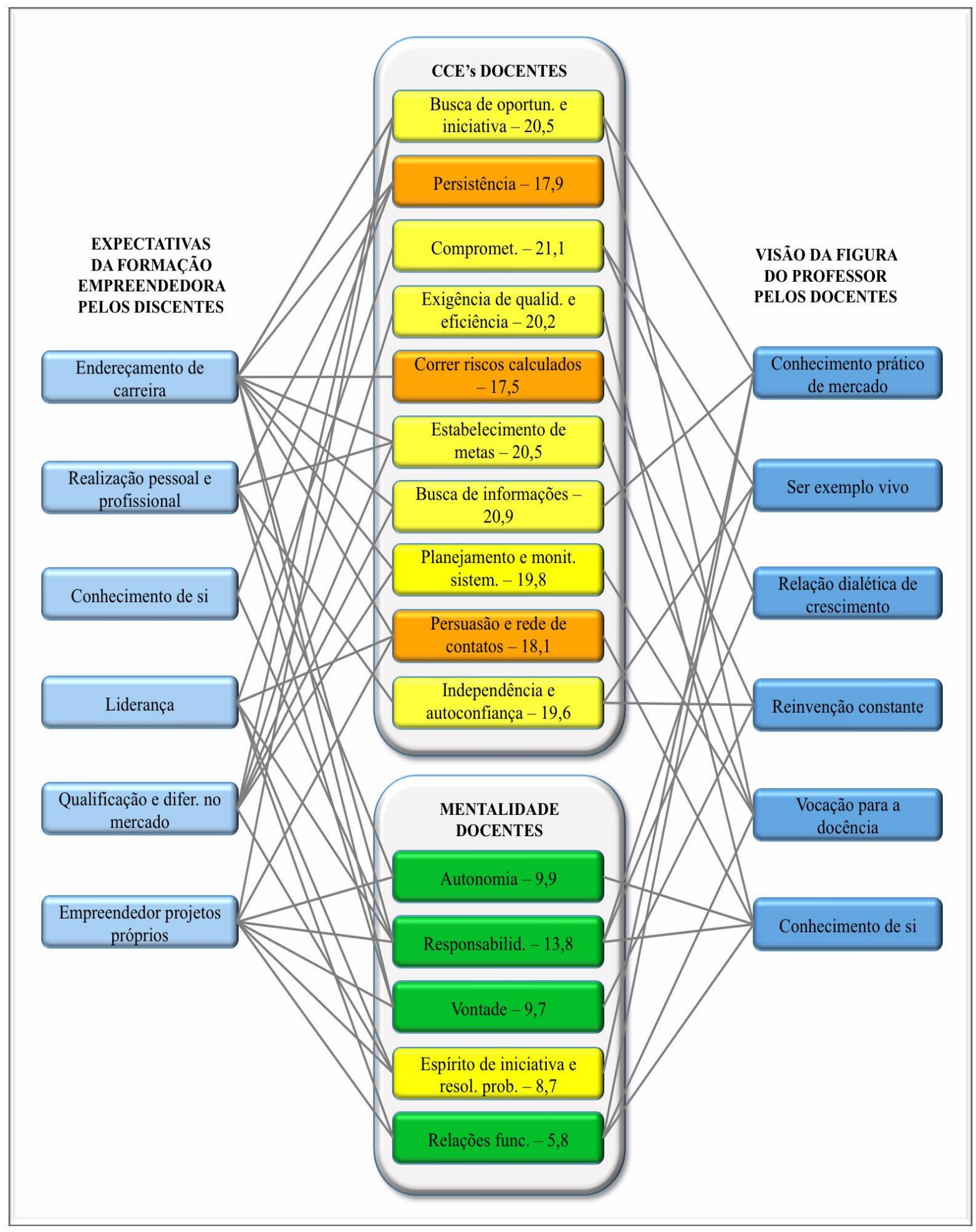

Fonte: elaborado pelos autores.

Pode-se inferir, a partir desses resultados, que existe uma relação direta entre a visão que os professores têm da educação empreendedora e seu papel no processo com suas características comportamentais e dimensões da mentalidade empreendedora. O conhecimento prático e aplicado de mercado, a atitude 
de buscar ser um exemplo vivo daquilo que ensina, a relação dialética de crescimento junto com os alunos, a busca de reinvenção e renovação constante, a vocação para a docência e o conhecimento de si estão todos relacionados com as características comportamentais empreendedoras e as dimensões da mentalidade empreendedora mensuradas. As características que ainda são baixas entre os docentes investigados (persistência, correr riscos calculados, e persuasão e rede de contatos) podem ser aumentadas se esses aspectos reconhecidos pelos próprios docentes forem intensificados. Do mesmo modo, as expectativas dos alunos em relação à formação docente convergem com os dados levantados dos professores. O endereçamento da carreira profissional, a realização progressiva como pessoa e como profissional, um maior conhecimento de si mesmo, o desenvolvimento da liderança, a qualificação e diferenciação no mercado de trabalho e a possibilidade de empreender o próprio negócio são resultados que podem ser alcançados por meio da educação empreendedora se os docentes envolvidos com ela assumirem o seu papel no processo, desenvolvendo progressivamente também eles o comportamento e a mentalidade empreendedoras.

Foram também cruzadas as considerações relacionadas aos resultados esperados pelos professores com os resultados relatados pelos alunos, provenientes da abordagem qualitativa, com as médias das características comportamentais empreendedoras e das dimensões da mentalidade empreendedora dos alunos, provenientes da abordagem quantitativa. A Figura 14 ilustra estes resultados de modo esquemático. 
Figura 14 - Associação entre os resultados buscados pelos docentes, características comportamentais e mentalidade empreendedoras e resultados alcançados pelos discentes

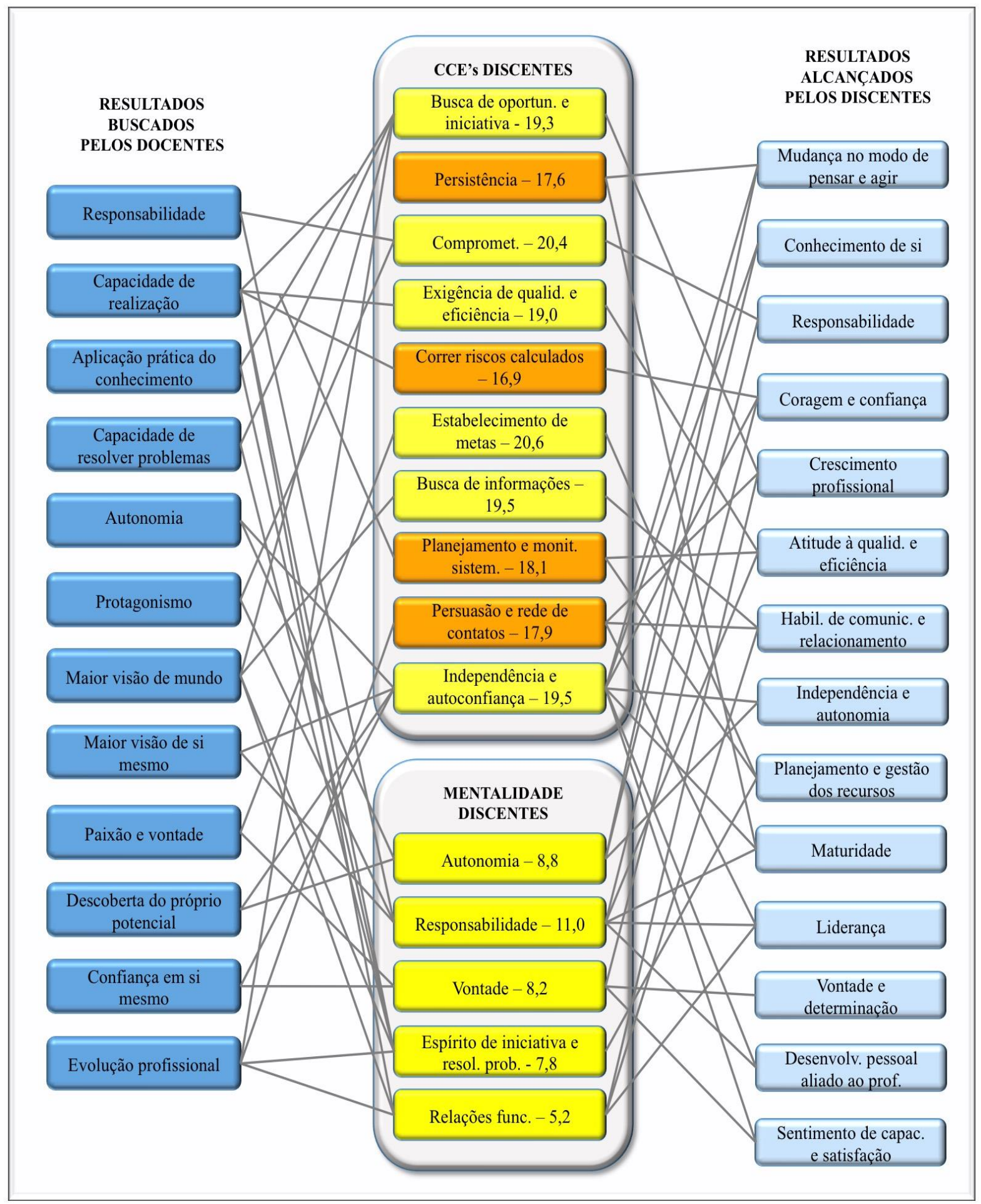

Fonte: elaborado pelos autores.

A partir desses resultados, pode-se inferir que existe uma associação direta entre os resultados buscados pelos professores e aqueles alçados pelos alunos. Se a educação empreendedora for continuada, e intensificada, ao longo da graduação, pode-se supor que as dimensões trabalhadas e buscadas pelos professores (responsabilidade, capacidade de realização, autonomia, protagonismo, maior visão de mundo e de si mesmo, paixão e vontade, descoberta do próprio potencial, confiança em si mesmo, e 
evolução profissional) levarão ao desenvolvimento das características comportamentais e mentalidade empreendedora dos alunos, mensuradas pelos instrumentos quantitativos e, em sua maior parte, ainda com intensidades médias. Além disso, aspectos da mentalidade identificados nos alunos (como responsabilidade, autonomia, maior visão de si mesmo e do mundo, vontade e determinação, confiança em si mesmo etc.) e aspectos do comportamento (como capacidade de realização, capacidade de resolver problemas, habilidades de comunicação e relacionamento, liderança, capacidade de aplicar o conhecimento etc.) podem se desenvolver reciprocamente durante a educação empreendedora.

Em relação à análise de conteúdo realizada a partir das entrevistas com os docentes, as duas últimas categorias não a priori ("Empreender como forma de ser, saber e fazer" e "Resultados da educação empreendedora") relacionam-se também ao quarto objetivo específico da pesquisa.

Empreender torna-se uma forma de ser, de saber e de fazer, com características de mentalidade (modo de pensar) e de comportamento (modo de agir) sendo desenvolvidas tanto nos alunos quanto nos professores, enquanto indivíduos empreendedores (modo de ser). Para que se atinjam esses resultados, é importante que o potencial natural de cada indivíduo seja reconhecido e continuamente reforçado (Giordani \& Mendes, 2011; Dolabela \& Filion, 2013; Wazlawick, 2016; Wazlawick et. al., 2017). Ampliando a visão de mundo e de si mesmo, o aluno pode assumir uma postura de protagonista responsável diante das situações com que se depara, sendo vetor de transformação e evolução do seu contexto (Lopes \& Teixeira, 2010; Nassif; Hanashiro \& Torres, 2010).

Desse modo, a educação empreendedora desenvolve a mentalidade e características comportamentais empreendedoras tanto nos alunos quanto nos professores, ao longo de todo o processo, por meio de um crescimento mútuo, contínuo e compartilhado. Como uma formação que desenvolve as dimensões do ser, saber e fazer empreendedor, tem como resultado o desenvolvimento e a realização tanto pessoal quanto profissional dos envolvidos, no sentido de que várias instâncias e características do indivíduo empreendedor são estimuladas e evoluídas. Esse desenvolvimento complementar e progressivo leva à formação do autoconceito e da identidade do empreendedor. E a descoberta do próprio potencial, como buscam os docentes, ou o conhecimento de si, como relatam os alunos, é um dos fundamentos a partir do qual se pode desenvolver de modo autêntico o indivíduo empreendedor (Dolabela \& Filion, 2013; Spanhol \& Boer, 2015).

A partir dessas constatações, pode-se inferir que uma educação empreendedora que contemple todas essas dimensões pode desenvolver, de modo concreto, o "saber conhecer", o "saber aprender", o "aprender a aprender", o "saber fazer", o "saber passar a ação", o "saber conviver", descrito por vários autores referenciados ao longo desta pesquisa. Baseado no "saber ser", o indivíduo pode chegar ao "saber tornar-se", por meio de uma educação empreendedora que possibilite de modo concreto a evolução do "ser empreendedor".

\section{Considerações finais}

O presente estudo teve o objetivo de analisar o desenvolvimento da mentalidade e do comportamento empreendedores em alunos e professores de graduação de uma instituição privada de ensino superior, por meio da educação empreendedora voltada para o empreender como uma forma de ser, saber e fazer. Pode-se constatar que este objetivo foi atingido a partir das iniciativas de educação empreendedora identificadas tanto nos relatos dos alunos, obtidos por meio da pesquisa informal, quanto nas entrevistas, realizadas com os professores. Pode-se verificar, seja nas falas dos docentes seja dos discentes, as características e especificidades da natureza da educação empreendedora, os novos papéis e funções que os alunos e professores assumem com ela e as novas metodologias e práticas didático-pedagógicas voltadas à formação empreendedora. Além disso, os relatos obtidos com esta pesquisa evidenciam também os resultados buscados e alcançados, tanto pelos discentes, quanto pelos docentes, de uma educação empreendedora não apenas orientada à transmissão e aquisição de conhecimentos, mas sobretudo voltada ao empreender como uma forma de ser, saber e fazer. Esses 
resultados da abordagem qualitativa foram corroborados pelos resultados da abordagem quantitativa, que identificaram e quantificaram nos docentes e nos discentes, por meio do questionário Forma mentis de Mencarelli (2014), as dimensões da mentalidade empreendedora e, por meio do questionário de McClelland (MSI, 1990), as características do comportamento empreendedor.

Para avançar no alcance do objetivo da pesquisa, realizou-se também a triangulação dos dados provenientes das abordagens qualitativa e quantitativa. Foram cruzadas as expectativas dos alunos em relação à educação empreendedora, identificadas a partir da pesquisa informal, com a visão dos professores em relação à formação empreendedora e seu papel como docentes, provenientes da análise de conteúdo, associadas às características comportamentais e mentalidade empreendedoras dos docentes obtidas por meio dos questionários. Na sequência, foram também cruzados os resultados esperados pelos docentes em relação à formação empreendedora dos alunos, provenientes da análise de conteúdo, com os resultados alcançados pelos alunos, verificados tanto nos depoimentos da pesquisa informal quanto nas características comportamentais e mentalidade empreendedoras mensuradas por meio dos questionários. Os resultados obtidos com essa triangulação evidenciaram associações diretas entre as expectativas dos alunos em relação à educação empreendedora, os resultados que têm obtido, as intensidades das dimensões da mentalidade empreendedora e características comportamentais empreendedoras, com aquilo que os professores buscam desenvolver nos alunos, o que e como fazem para isso, os resultados que têm alcançado também para si mesmos e as dimensões da mentalidade empreendedora e características comportamentais empreendedoras aferidas entre os docentes.

A educação empreendedora percorreu um longo caminho nos últimos anos e se disseminou em práticas pedagógicas, disciplinas e programas de formação, porém, como visto ao longo deste estudo, as pesquisas sobre a temática ainda necessitam de mais investigações teóricas e empíricas. Nas últimas décadas, os estudos sobre "empreendedorismo" avançaram bastante em termos de visibilidade e importância, porém o tema da "educação empreendedora" ainda carece de uma discussão mais embasada e sólida, que auxilie no seu amadurecimento e norteamento, e estimule a sua disseminação de forma mais ampla e eficaz.

Há uma necessidade de se analisar melhor o que é a educação empreendedora, buscando compreensões em relação a questionamentos como: Como os empreendedores aprendem? Como a capacidade empreendedora se desenvolve? O que ensinar? De que forma? Como potencializar e facilitar essas aprendizagens? Quais técnicas e estratégias pedagógicas são as mais adequadas para o contexto brasileiro? Como adotá-las com eficiência nas instituições de ensino superior? Esta pesquisa buscou contribuições teóricas e práticas para estas questões, visto que respostas a tais questionamentos e uma maior compreensão sobre esse processo permitirão indicar como formatar instrumentos, práticas didático-pedagógicas e atividades condutoras à educação de indivíduos empreendedores.

Em relação à mentalidade e comportamento empreendedores, pode-se constatar, com base nos vários estudos reunidos e confrontados nesta pesquisa, que empreender é um processo essencialmente humano. Uma maior compreensão dessa natureza empreendedora tem sido investigada cientificamente e o desenvolvimento do espírito empreendedor tem sido colocado como prioritário nas agendas e debates políticos, econômicos e acadêmicos de diversos países, tendo em vista a influência positiva que a atividade empreendedora exerce no desenvolvimento social e econômico de uma nação. Nessa direção e com este objetivo, para uma maior compreensão das ações e do comportamento dos indivíduos empreendedores, um dos elementos-chave que ainda precisa ser melhor compreendido são os processos que estão na base do seu pensamento (forma mentis), os processos a partir dos quais a ação empreendedora é inicialmente concebida e, em seguida, realizada.

Esta pesquisa se propôs a unir esforços nesse sentido, por meio de contribuições teóricas e práticas, buscando um maior entendimento da mentalidade empreendedora. A compreensão da natureza empreendedora e de como pensa e age o indivíduo empreendedor pode nortear as ações a serem 
realizadas com o propósito de criar sujeitos, organizações e ambientes empreendedores, que gerem desenvolvimento humano, crescimento econômico e avanço social.

Este estudo se limitou aos instrumentos de coleta desenvolvidos por McClelland para avaliar as características do comportamento empreendedor e por Mencarelli para verificar as dimensões da mentalidade empreendedora em um corte transversal. Estudos futuros podem contemplar novos instrumentos para aferir o modo de pensar e de agir dos indivíduos empreendedores, ou ainda utilizar os mesmos instrumentos de coleta adotados nesta pesquisa, porém em um estudo longitudinal, a fim de se verificar se existem mudanças e evolução no desenvolvimento da mentalidade e comportamento empreendedores.

Os dados desta pesquisa também limitaram-se à cultura brasileira, por meio da análise de docentes e discentes de uma instituição privada de ensino superior. Há de se ter cautela, portanto, em relação à generalização dos resultados. Sugere-se, para ampliar esta abrangência e permitir verificações e confrontos, que os procedimentos metodológicos adotados neste estudo sejam replicados em novas pesquisas em outras instituições de ensino, tanto públicas quanto privadas. Estudos comparados de iniciativas de educação empreendedora e desenvolvimento da mentalidade e comportamento empreendedores podem trazer benefícios para a gestão, ensino, pesquisa e extensão de instituições tanto públicas quanto privadas. Além disso, estudos futuros sobre o tema abordado nesta pesquisa podem ser realizados em outros países a fim de contribuir para um maior entendimento sobre as especificidades da formação empreendedora no Brasil, bem como permitir uma troca de entendimentos e boas práticas entre instituições de diferentes nacionalidades.

\section{Referências}

Amaral, M., Hernandez, C. T. \& Bastos, M. R. H. (2018). The entrepreneurial profile of Brazilian business administration students. International Journal of Innovation Science, 10(2), 160-177.

Araujo, G., \& Davel, E. (2019). Educação Empreendedora pela Experiência: O Caso do Festival de Artes Empreendedoras em Itabaiana. REGEPE - Revista de Empreendedorismo e Gestão de Pequenas Empresas, 8(1), 176-200.

Bardin, L. (2011). Análise de Conteúdo. Lisboa, Portugal: Edição 70.

Barini Filho, U. (2008). Transmissão da competência empreendedora: um estudo de casos múltiplos. (Tese de Doutorado). Universidade de São Paulo, São Paulo, SP, Brasil.

Carrara, C. (2014). Entrepreneur's forma mentis as a factor of economic success. In: Dmitrieva, V. (Org.). The man in dialogue with the surrounding world: an ontopsychological approach. São Petersburgo: Imprensa Universitária.

Chikota, H.; Miranda, C. \& Wazlawick, (2016). P. Adolescence and Identity: how avoidin dysfunctional behaviours. p. 487. In: International Journal of Psychology. 31 st. Internationa Congress of Psychology. Yokohama: International Union of Psychologial Scienc.

Coan, M. (2011). Educação para o empreendedorismo: implicações epistemológicas, políticas e práticas. (Tese de Doutorado). Universidade Federal de Santa Catarina, Florianópolis, SC, Brasil.

De Toni, D., Mioranza, G., Milan, G. S. \& Larentis, F. (2014). As dimensões dos modelos mentais dos empreendedores e seus impactos sobre o desempenho organizacional. READ - Revista Eletrônica de Administração, 79(3), 713-739.

Denzin, N. (1978). The research act: a theoretical introduction to sociological methods. 2. ed. Nova York: Mc Graw-Hill.

Dolabela, F. (2008). Oficina do empreendedor. Rio de Janeiro: Sextante.

Dolabela, F. \& Filion, L. J. (2013). Fazendo revolução no Brasil: a introdução da pedagogia 
empreendedora nos estágios iniciais da educação. Revista de Empreendedorismo e Gestão de Pequenas Empresas, 3(2), 134-181.

Duarte, L. S., Debona, M. \& Perini, R. L. (2018) Perfil empreendedor do acadêmico do centro de negócios do Centro Universitário da Serra Gaúcha (FSG). Revista Global Manager Acadêmica, 7(1), 576599.

educação. São Paulo: Atlas, 2008.

Filion, L. J. \& Lima, E. (2010). As representações empreendedoras: importantes temas para avançar em seus estudos. Revista de Negócios, 15(2), 32-52.

Fillion, L. J. (1991). O planejamento do seu sistema de aprendizagem empreendedora: identifique uma visão e avalie o seu sistema de relações. Revista de Administração de Empresas, 31, (3), 63-72.

Fillion, L. J.; Dolabela, F. (2007). The making of a revolution in Brazil: the introduction of entrepreneurial pedagogy in the early stages of education. In.: Fayolle, A. (Ed.) Handbook of Research in Entrepreneurship Education, Vol. 2, Cheltenham, UK/ Northampton, MA, USA, Edward Elgar. 13-39.

Giordani, E. M. \& Mendes, A. M. M. (2011). Pedagogia ontopsicológica na orientação do estágio dos anos iniciais do ensino fundamental. Nuances: estudos sobre educação, 20(21), 43-62.

Guaranys, L. R.. (2010). Universidade empreendedora: conceito em evolução, universidade em transformação. In: Lopes, R. M. A. (Org.). Educação empreendedora: conceitos, modelos e práticas. Rio de Janeiro: Elsevier: São Paulo: SEBRAE.

Guerra, M. J. \& Grazzotin, Z. J. (2010). Educação empreendedora nas universidades brasileiras. In: Lopes, R. M. A. (Org.). Educação empreendedora: conceitos, modelos e práticas. Rio de Janeiro: Elsevier: São Paulo: SEBRAE.

Hair Jr., J. F.; Babin, B., Money, A. H. \& Samouel, P. (2005). Fundamentos de métodos de pesquisa em Administração. São Paulo: Artmed.

Henrique, D. C. \& Cunha, S. K. (2008). Práticas didático-pedagógicas no ensino de empreendedorismo em cursos de graduação e pós-graduação nacionais e internacionais. RAM - Revista de Administração Mackenzie, 9(5), 112-136.

Hirsch, R. D., Peters, M. P.\& Shepherd, D. A. (2014). Empreendedorismo. (9.) Porto Alegre: AMGH.

Krüger, C. (2019). Modelo de mensuração do comportamento empreendedor a partir das características comportamentais e intenção empreendedoras. (Tese de Doutorado). Universidade Federal de Santa Maria, Santa Maria, RS, Brasil.

Krüger, C. \& Minello, I. F. (2017). Educação empreendedora: características e atitudes. Sarbrücken: Novas Edições Acadêmicas.

Krüger, C., Pinheiro, J. P. \& Minello, I. F. As características comportamentais empreendedoras de David McClelland. Revista Caribeña de Ciencias Sociales, 2017.

Leiva, J. C., Monge, R. \& Alegre, J. (2014). The Influence of Entrepreneurial Learning in New Firms' Performance: A Study in Costa Rica. Innovar, 24 (N. Especial), 129-140.

Lima, E., Hashimoto, M., Melhado, J. \& Rocha, R. (2014a). Brasil: em busca de uma educação superior em empreendedorismo de qualidade. In: Gimenez, F. A. P. et. al. (org.) Educação para o empreendedorismo. Curitiba: Agência de Inovação da UFPR.

Lima, E., Lopes, R. M. A., Nassif, V. M. J. \& Silva, D. (2015a). Oportunities to improve entrepreneurship education: contributions considering Brazilian Challenges. Journal of Small Business Management, 53(4), 1033-1050.

Lima, E., Lopes, R. M. A., Nassif, V. M. J. \& Silva, D. (2015b). Ser seu Próprio Patrão? Aperfeiçando- 
se a educação superior em empreendedorismo. $R A C, 19(4), 419-439$.

Lima, E., Nassif, V. M. J., Lopes, R. M. A. \& Silva, D. (2014b). Educação Superior em Empreendedorismo e Intenções Empreendedoras dos Estudantes - Relatório do Estudo GUESSS Brasil. Caderno de pesquisa, n. 2014-03. São Paulo: Grupo APOE.

Lima, L. G.; Nassif, V. M. J. (2017). Similitudes entre teoria social cognitiva, capital psicológico e comportamento empreendedor: uma reflexão teórica. Revista Gestão e Planejamento, 18.

Lopes, L. F. D. (2016). Métodos quantitativos. Santa Maria: Universidade Federal de Santa Maria.

Lopes, R. M. A. (2010). Referenciais para a educação empreendedora. In: Lopes, R. M. A. (Org.). Educação empreendedora: conceitos, modelos e práticas. Rio de Janeiro: Elsevier.

Lopes, R. M. A. \& Teixeira, M. A. A. (2010). Educação empreendedora no ensino fundamental. In: Lopes, R. M. A. (Org.). Educaşão empreendedora: conceitos, modelos e práticas. Rio de Janeiro: Elsevier.

Mansfield, R., S., McClelland, D. C., Spencer, L. M. \& Santiago, J. (1987) The identification and Assessment of competencies and other personal characteristics of entrepreneurs in Developing Countries. Boston: McBer\&Company.

Matias, M. A. \& Martins, G. A. (2012). Educação empreendedora em contabilidade. RBC: Revista Brasileira de Contabilidade, 41, 41-53.

McClelland, D. C. (1972). A sociedade competitiva: realização e progresso social. Rio de Janeiro: Expressão e Cultura.

McClelland, D. C. (1978). Managing motivation to expand human freedom. American Psychologist, 33(1). 201-210.

McClelland, D. C. (1987). Characteristics of Successful Entrepreneurs. The Journal or Creative Behavior, 21(3). 219-233.

Mencarelli, C. Test "Forma mentis". (2014). In: Dmitrieva, V. (Org.). The man in dialogue with the surrounding world: an ontopsychological approach. São Petersburgo: Imprensa Universitária.

Mendes, M. T. T. (2011). Educação Empreendedora: uma visão holística do empreendedorismo na educação. (Dissertação de Mestrado em Ciências da Educação). Universidade Católica Portuguesa, Lisboa, Portugal.

Meneghetti, A. (2013). A psicologia do líder. 5. ed. Recanto Maestro: Ontopsicológica Editora Universitária.

Minayo, M. C. S. \& Costa, A. P. (2018). Fundamentos Teóricos das Técnicas de Investigação Qualitativa. Revista Lusófona de Educação, 40(40), 139-153.

MSI - Management Systems International. Final Report: entrepreneurship training and the strengthening of entrepreneuria performance. 1990.

Nabi, G., Walmsley, A., Linan, F., Akhtar, I. \& Neame, C. (2018). Does entrepreneurship education in the first year of higher education develop entrepreneurial intentions? The role of learning and inspiration. Studies in Higher Education, 43(3), 452-467.

Nassif, V. M. J, Hanashiro, D. M. M. \& Torres, R. R. (2010). Fatores que influenciam na percepção das competências para o exercício da docência. Revista Brasileira de Educação, 15(44), 364-379.

Nassif, V., Amaral, D., Pinto; C.; Soares, M. \& Pando, R. A. (2009). Formação empreendedora: aspectos convergentes e divergentes sob a ótica de alunos, professores, pais e empreendedores. ANGRAD, 10(2), 73-96.

Patton, M. Q. (2002). Qualitative Research and Evaluation Methods. Thousand Oaks, CA: Sage Publications. 
Rabelo, A. O. (2010). "Eu gosto de ser professor e gosto de crianças" - A escolha profissional dos homens pela docência na escola primária. Revista Lusófona de Educaşão, (15), 163-173.

Ribas, R. (2011). O saber empreendedor: diretrizes curriculares para elaboração de programas para formação de empreendedores com base na Escola Progressiva de John Dewey - reflexão e proposta. (Tese de Doutorado), Pontifícia Universidade Católica de São Paulo, São Paulo, SP, Brasil.

Rocha, E. L. C. \& Freitas, A. A. F. (2014). Avaliação do Ensino de Empreendedorismo entre Estudantes Universitários por meio do Perfil Empreendedor. RAC, 18(4), 465-486.

Sampieri, R. H., Collado, C. F. \& Lucio, M. P. B. (2013). Metodologia de Pesquisa. (5.) Porto Alegre: Penso.

Schaefer, R. (2018). Empreender como uma forma de ser, saber e fazer: o desenvolvimento da mentalidade e do comportamento empreendedores por meio da educação empreendedora. (Tese de Doutorado). Universidade Federal de Santa Maria, Santa Maria, Brasil.

Schaefer, R. \& Minello I. F. (2016). Educação Empreendedora: Premissas, Objetivos e Metodologias. Revista Pensamento Contemporâneo em Administração, 10(3), 60-81.

Schaefer, R. \& Minello I. F. (2017a). A Formação de Novos Empreendedores: Natureza da Aprendizagem e Educação Empreendedoras. Revista da Micro e Pequena Empresa - FACCAMP, 11, 2-20.

Schaefer, R. \& Minello I. F. (2017b) Mentalidade empreendedora: o modo de pensar do indivíduo empreendedor. Revista de Empreendedorismo e Gestão de Pequenas Empresas, 6(3), 495-524.

Schaefer, R. \& Minello, I. F. (2019) Entrepreneurial education: entrepreneurial mindset and behavior in undergraduate students and professors. Revista de Negócios, 24(2), 61-90.

Silva, J. F. \& Pena, R. P. M. (2017). O “be-á-bá” do ensino do empreendedorismo: uma revisão da literatura sobre os métodos e práticas da educação empreendedora. Revista de Empreendedorismo e Gestão de Pequenas Empresas, 6(2), 372-401.

Spanhol, C. I. A. \& Boer, N. (2015). Método Ontopsicológico: contribuições à formação continuada na perspectiva de professores do ensino superior. Saber Humano, 5(7), 53-69.

Triviños, A. N. S. (2008). Introdução à pesquisa em ciências sociais: a pesquisa qualitativa em educação. São Paulo: Atlas.

Tschá, E. R. \& Cruz Neto, G. G. (2014). Empreendendo colaborativamente ideias, sonhos, vidas, e carreiras: o caso das células empreendedoras. In: GIMENEZ, F. A. P. et. al. (org.) Educação para o empreendedorismo. Curitiba: Agência de Inovação da UFPR.

Vergara, S. C. (2012). Métodos de Pesquisa em Administração. 5. ed. Atlas.

Volkova, E.; Dmitrieva, V.; Mikhalyuk, O.; Vereitnova, T.; Wazlawick, P.; Schaefer, R.; Silva, J.; Salles, P. (2016). Sobre a socialização dos jovens modernos: breve discussão entre conceitos da Sociologia, da Psicologia Social e Histórico-Cultural. Revista Eletrônica do Mestrado em Educação Ambiental, 33, 331-343.

Wazlawick, P. (2016). Pensiero filosofico della Cultura Umanistica come pressupposto alla Pedagogia Ontopsicologica: resultati del percorso formativo dei giovani nell'educazione universitaria. Saber Humano, 6(8), 29-71.

Wazlawick, P.; Schaefer, R.; Volkova, E.; Dmitrieva, V.; Vereitnova, T. \& Mikhalyuk, O. (2017). Para a definição do conceito de socialização positiva de jovens. Revista Interdisciplinar Científica Aplicada, 11(2), 78-100.

Wood, M. S., Williams, D. W. \& Drover, W. (2017). Past as prologue: Entrepreneurial inaction decisions and subsequent action judgments. Journal of Business Venturing, 32, 107-127.

Yin, R. K. (2016). Pesquisa qualitativa do início ao fim. Editora Penso: Porto Alegre. 